\title{
Development Assistance, Institution Building, and Social Cohesion after Civil War: Evidence from a Field Experiment in Liberia
}

\section{James Fearon, Macartan Humphreys, and Jeremy M. Weinstein*}

\begin{abstract}
Can brief, foreign-funded efforts to build local institutions have positive effects on local patterns of governance, cooperation, and well-being? Prior research suggests that such small-scale, externally driven interventions are unlikely to substantially alter patterns of social interaction in a community, and that the ability of a community to act collectively is the result of a slow and necessarily indigenous process. We address this question using a randomized field experiment to assess the effects of a community-driven reconstruction (CDR) project carried out by the International Rescue Committee (IRC) in northern Liberia. The project attempted to build democratic, community-level institutions for making and implementing decisions about local public goods. We find powerful evidence that the program was successful in increasing social cohesion, some evidence that it reinforced democratic political attitudes and increased confidence in local decision-making procedures, but only weak evidence that material well-being was positively affected. There is essentially no evidence of adverse effects. *Jeremy Weinstein is on leave from the Center for Global Development.
\end{abstract}




\title{
Development Assistance, Institution Building, and Social Cohesion after Civil War: Evidence from a Field Experiment in Liberia
}

\author{
James Fearon \\ Stanford University \\ Macartan Humphreys \\ Columbia University \\ Jeremy M. Weinstein \\ Stanford University and Center for Global Development (on leave)
}

The authors thank Liz McBride and Jodi Nelson of IRC for their leadership and assistance; Johnson Kei of the Liberia Institute of Statistics and GeoInformation Services (LISGIS) and Gwen Taylor of NYU for overseeing the administration of the first wave of the panel survey; K. Johnson Borh, Morlee Gugu Zawoo Sr., Zeleh Zealous Kolubah and Johannson Q Dahn of National Ex-Combatant Peacebuilding Initiatives (NEPI) and Gwen Taylor of NYU for overseeing the administration of the second wave survey; and NEPI and Nicholai Lidow of Stanford University (supported by Andrea Abel, Jessica Gottlieb, and Amanda Robinson) for overseeing the administration of the behavioral games. All of these teams did extraordinary work in very difficult conditions. We are also grateful for the support of a number of funders that made this impact evaluation possible. DFID provided the bulk of funding for the panel survey: The Center for Global Development provided additional funding for the second wave survey; AusAID, through a grant to the Center for Global Development, provided the resources to implement the behavioral protocol for the measurement of social cohesion; and the Center for Democracy, Development, and the Rule of Law provided funding for field work expenses. The views expressed in this paper are the authors' views and do not necessarily reflect the views of the U.S. government.

James Fearon, Macartan Humphreys, and Jeremy M. Weinstein. 2009. "Development Assistance, Institution Building, and Social Cohesion after Civil War: Evidence from a Field Experiment in Liberia." CGD Working Paper 194. Washington, D.C.: Center for Global Development. http://www.cgdev.org/content/publications/detail/1423322

Center for Global Development 1800 Massachusetts Ave., NW Washington, DC 20036

202.416 .4000

(f) 202.416 .4050

www.cgdev.org
The Center for Global Development is an independent, nonprofit policy research organization dedicated to reducing global poverty and inequality and to making globalization work for the poor. Use and dissemination of this Working Paper is encouraged; however, reproduced copies may not be used for commercial purposes. Further usage is permitted under the terms of the Creative Commons License.

The views expressed in this paper are those of the author and should not be attributed to the board of directors or funders of the Center for Global Development. 


\section{Introduction}

It is broadly accepted among both academics and policymakers that a society's institutional environment (or "social infrastructure") is a key determinant of patterns of economic growth and poverty reduction. From this perspective, institutions that protect property rights and the rule of law are particularly conducive to desirable economic behavior. Consequently, bilateral and multilateral donors increasingly target significant resources toward support for "good governance" - through investments in the reform of bureaucracies, the strengthening of institutions that check the power of the executive branch, and the creation of local institutions to foster development. Strategies to generate and reform institutions are a particularly prominent approach in fragile states where undemocratic practices and corruption are common.

A significant share of this assistance is spent on "community-driven reconstruction" (CD R) programs designed to promote social reconciliation and better governance at the local level. Whether this assistance has the positive effects attributed to it is largely unknown. Indeed by some accounts, the engagement of international actors could have adverse effects on local governance. Can external interventions of this form alter local political dynamics and promote social cohesion? Can brief, foreign-funded interventions that aim to build local institutions to improve governance have positive or indeed any effects on local patterns of cooperation and wellbeing?

We address this question using a randomized field experiment to assess the effects of a CD R project carried out by the International Rescue Committee (IRC) in northern Liberia. The project attempted to build democratic, community-level institutions for making and implementing decisions about local public goods. This model of support for participatory processes to enhance local public goods provision is now standard in post-conflict contexts, and is also a key component of donor funded efforts to reduce poverty ("community-driven development").

Prior research suggests that small-scale, externally-driven interventions are unlikely to fundamentally alter patterns of social interaction in a community, and that institution building is a slow and necessarily indigenous process. Scholars have argued that norms of social interaction are an outcome of long-run evolutionary mechanisms (Bowles and Gintis 2004); have deep historical roots in critical junctures that reshape social relations, such as the extraction of slaves from Africa (Nunn 2008); or reflect relatively fixed characteristics of communities, such as ethnic heterogeneity or the distribution of wealth (Alesina and La Ferrara 2005). In addition, aid workers often return from the field demoralized by an impression that the benefits of foreign aid projects are easily captured by existing power brokers, a view that resonates with findings by economists (Gugerty and Kremer 1998) and anthropologists (Murphy 1990 and Ensminger 2007). Moreover, aid critics contend that aid interventions may simply stifle local initiative and breed dependency and corruption (Moyo 2009).

Yet the intervention we examine here is premised on the notion that increased cooperation and improved wellbeing can result from even a brief exposure to participatory politics - through an externally designed CD R program that involves the organization of community committee structures and support for those structures to help meet community needs. We exploit this 
intervention in an effort to assess whether patterns of social cooperation are actually responsive to these new institutions, even when underlying demographic, economic, and political factors remain unchanged.

The data we have to assess the impact of the CD R program are rich, consisting of baseline and follow-up surveys and behavioral data collected from public goods games played by 1979 randomly sampled individuals in the summer of 2008. Results from the panel survey of households - conducted before and after the CD R project - provide evidence largely consistent with the CD R project having had a positive impact on beneficiary communities. Survey data suggest that the program reduced social tension, increased the inclusion of marginalized groups, and enhanced individuals' trust in community leadership. The survey provides much weaker evidence that the program positively reinforced support for democracy, had an impact material well-being, or resulted in an increased ability of the community to act collectively and no evidence that the attitudes of traditional leaders towards decision making was affected in any way.

The behavioral measures reinforce the survey results on cohesion in a powerful way. Measures of cohesion are generated by examining the actual behavior of community members in collective action problems facing their communities in both program and comparison areas. The results provide strong evidence that the CD R program did alter patterns of social cooperation and reinforced support for democratic practices, even after the program's conclusion. Villages exposed to the IRC's CD R program were found to exhibit higher subsequent levels of social cooperation than those in the control group and to employ more democratic practices for community decisionmaking, as measured through a community-wide public goods game.

We believe that this is the first time a CD R project of this form has been evaluated with a randomized control trial (although other such trials are ongoing). We are sure that this is first time that a CD R evaluation has attempted to assess changes in actual behavior - as opposed to changes in survey responses - concerning community governance and ability to cooperate to provide public goods. The evidence of positive program impact, and absence of evidence of negative impact in measured areas, is thus considerably stronger than previous evaluation work done on CD R programming.

\section{Evaluating the Impact of Community-Driven Reconstruction}

Community-driven reconstruction (CD R), or community-driven development (CDD) as it is referred to more broadly, is rapidly gaining popularity as a mechanism for delivering development assistance. Such programs emphasize the engagement of beneficiaries in the design and management of development projects, often by giving communities direct control over key project decisions.

By some estimates, the World Bank's lending alone for CDD projects exceeded $\$ 2$ billion in 2003 (Mansuri and Rao 2004). Bilateral donors have also embraced the methodology, applying it to support local public goods provision in areas as diverse as infrastructure, agriculture, health care, and education. Community-driven development is viewed widely as a mechanism for making development more inclusive, empowering the poor, strengthening governance, and enhancing project effectiveness and sustainability.

As Mansuri and Rao suggest (2004), there is significant potential for community-driven processes to transform social relations. CD R and CD D programs have, as an explicit purpose, the 
goal of challenging existing structures of authority by putting power and resources in the hands of community members, especially previously disadvantaged or marginalized groups. They typically contain two major components: first, the democratic selection of community committees and second, the allocation of block grants to be spent on development within communities with project selection and oversight led by the community committees (Cliffe et al 2003). In this way, they involve both the creation of new institutions and an opportunity for the population to observe these institutions in action.

Skeptics have countered that such approaches are easily captured by local elites; risk undermining existing (and sometimes democratically-elected) institutions; or inevitably sacrifice the time-consuming work of community mobilization and empowerment to the task of implementing big budget development projects on short timelines.

In light of the rapid scale-up of these programs, there is surprisingly little evidence of their impact. A now, somewhat dated review of existing evaluations commissioned by the World Bank (2003) found only mixed evidence that CD D programs strengthen the targeting of beneficiaries, enhance service delivery, and improve sustainability; moreover, the review unearthed little evidence on whether projects better reflect community preferences and whether exposure to CDD increases the capacity for subsequent collective action. More recent work (Arcand and Bassole 2007; Labonne and Chase 2008) has started to find more positive results. O ur evaluation builds on this work by examining CDD in a post-conflict setting (CDR), by examining direct measures of effects on social behavior, and by employing a first-best identification strategy, randomized evaluation.

\subsection{Community-Driven Reconstruction in Liberia}

In 2006, IRC launched a community-driven reconstruction program in Lofa County, Liberia. Northern Liberia figures centrally in the violence that engulfed Liberia over the past fifteen years. It was a hotspot during Charles Taylor's rebellion between 1990 and 1996 and reemerged as the epicenter of a second war against Taylor's government after 2000.

O ur baseline data testify to the extent of damage done to the region by the conflict. The data record information on almost 6,000 household members living in the region in 1989. Of these, over $4 \%$ are reported to have died directly from war related violence and a further $6 \%$ suffered injury or maiming. 5\% took active part in the fighting, with three fifths of these having been abducted. A similar share (4.9\%) of approximately 1500 subjects we interviewed in our follow up survey selfreported as ex-combatants. The most widespread effect, however, was one that could have a direct bearing on communities' ability to cooperate (Richards et al 2005): 85\% of these individuals were displaced during the conflict and many were displaced multiple times. Of 1500 individuals we interviewed in the final survey, 25\% still considered themselves internally displaced.

The CD R program had the following core components. First, villages were grouped into approximately equally-sized "communities" - based on geographic proximity and preexisting ties, each with a population of between 2000 and 3000 individuals. ${ }^{1}$ Then, the random assignment of the treatment took place. Following this, IRC undertook initial activities to sensitize local communities

\footnotetext{
${ }^{1}$ IRC oversaw this process and drew on its local knowledge of the area in making this aggregation. There are obviously differences across these "communities" in the extent of preexisting ties or the distance between included villages. We have not yet explored how this heterogeneity affects outcomes.
} 
to the new development project, including targeted meetings with local chiefs and elders to solicit their cooperation. In each community, IRC oversaw the election of community development councils (CD Cs), with representatives chosen from among all voting-age adults in the villages. CD Cs were then empowered to oversee a community-wide process to select and implement a quick impact project (approx $\$ 2000-\$ 4000$ in value), followed by a larger development project (approx $\$ 17,000$ in value). The members of the CDCs were selected in direct elections from among all voting age adults in the villages. CD Cs managed the implementation process and continue to have responsibility for project maintenance over time.

This model was adopted, in part, as a strategy for using local leadership to quickly generate material improvements in people's lives. Given the state of the government after fifteen years of civil war communities could plausibly also move more quickly than government to deliver a tangible peace dividend. Such participatory approaches are also argued for on the grounds that (a) people had lost faith in their government, both at the national and local level; (b) the conflict generated significant tensions and distrust within and across communities; and (c) that Liberian communities were struggling to incorporate marginalized and disenfranchised groups including internally displaced persons, women, young people, and ex-combatants (Richards et al 2005).

\subsection{Hypotheses about the Impact of CDR}

In this paper, we explore nine hypotheses that are implicit in the design of Liberia's CD R program. These hypotheses fall within three major families of outcomes: welfare, local governance, and community cohesion:

\section{Welfare:}

1.1 CD R will generate improved access to health, education, water sources, and other basic amenities.

1.2 CD R will result in greater opportunities for income generation and wealth creation.

\section{Local Govemance:}

2.1 CD R will change how individuals think about decision making at local levels, in favor of transparency, accountability, and inclusiveness.

2.2 CD R will change how leaders think about decision making at local levels, in favor of transparency, accountability, and inclusiveness.

2.3 CD R will change citizens' sense of personal efficacy and confidence that they can affect community decision making.

2.4 CD R will provide citizens with greater confidence in institutions for decision-making in their communities.

\section{Community Cohesion:}

3.1 CD R will result in greater acceptance of individuals, specifically conflict victims, displaced persons, and ex-combatants.

3.2 CDR will result in reduced tensions between groups and a greater ability to resolve tensions non-violently.

3.3 CD R will enhance the community's ability to act collectively.

These hypotheses emphasize the direct effects of CD R on community outcomes. It is also possible that CD R programs have broader impacts. For example, by improving public goods 
provision or enhancing cohesion, CD R may reduce the risk of renewed conflict by lessening local grievances or facilitating economic development, which may in turn reduce the incentives to participate in violence (World Bank 2003). These potential, indirect impacts were not a focus of the evaluation.

\subsection{Research Design}

In order to test these core hypotheses, we employed an approach known as randomized evaluation. To employ this approach, the IRC randomly assigned 42 communities to receive the CD R program. These communities were selected from among 83 equally-deserving and accessible "communities," constructed from over 400 villages that were clustered together (by IRC) on the basis of preexisting ties and geography in order to facilitate program implementation. This lottery was conducted in a public place, with chiefs representing each community in attendance.

This randomization process is key to ensure that differences in outcome measures for the project and comparison villages truly reflect the causal effects of the CD R program and not other features that determine selection into treatment in the first place. Those communities not exposed to CD R (the "control" communities) are, at least in expectation, no different than those who received the treatment, except for the fact of receiving treatment.

In practice, the randomization process was effective in the sense that baseline data shows that treatment and control areas are similar with respect to a large set of measures: exposure to conflict, community size, and so on. There are, however, some differences that arose by chance: specifically, treatment areas were somewhat more likely than control areas to be rural; likely related to this is the fact that treatment areas were on average located farther from health clinics than control areas, a feature we return to below. There is, moreover, some evidence for higher levels of political participation in treatment areas. Appendix A reports the characteristics of treatment and control communities as measured in our baseline survey.

Finally, it is important to emphasize that this impact evaluation does not isolate the impact of community-driven processes per se. Instead the evaluation identifies the overall impact of receiving funds for public goods provision coupled with a community-driven processes. In short, the design allows us to assess the effect of getting the IRC CD R program versus not getting the IRC CDR program. To assess the relative merits of a community-driven approach versus a more centralized strategy for implementation (e.g., perhaps by working through existing government institutions), a different research design would be required, in which different sorts of aid programming are assigned at random to different communities. Moreover, our research design uncovers the average impact of the community-driven reconstruction program across communities, though we recognize that the specific effects of the program may depend on how communities elected to spend their block grants. ${ }^{2}$ This average impact is nonetheless important, as programs of this type are designed explicitly to embrace community ownership of project selection.

\footnotetext{
${ }^{2}$ See Barron, Humphreys, Paler and Weinstein (2009) for a study of a case in which grants were administered in a very
} different manner with different results. 


\section{Measurement Strategy}

To assess the impact of the CD R program, we gathered data in three waves, drawing both on classic survey methods and a new approach to measuring behavioral change directly.

\subsection{Waves I and II: Panel Survey}

D uring the first wave of data collection (March/ April 2006), the team conducted a baseline survey of 1702 households. This was a representative sample of households in Voinjama and Zorzor districts, based on a sample frame produced by the United Nations Humanitarian Information Center. ${ }^{3}$ Because the survey was carried out before the IRC clustered villages into communities and selected treatment and control groups, a number of surveys were completed in areas that did not ultimately enter the sample used for the lottery. We were however able to link 1606 of the completed surveys in the baseline to their appropriate community in the IRC treatment and control group.

The second wave of data collection took place after the conclusion of the CD R program in March/ A pril 2008. The research team sought to find all households interviewed in the first wave, ultimately revisiting 1382 of the 1606 households (about 86\%) surveyed two years earlier. In addition, interviews were conducted with 166 new respondents, in an effort to ensure a minimum of 10 respondents in each of the IRC treatment and control communities. A parallel survey of 135 town and village chiefs was completed, targeting the chief in the major village associated with each IRC community and one additional randomly selected chief from among the other associated villages.

The surveys asked a battery of questions designed to measure outcomes including household and community welfare; progress toward the reintegration of ex-combatants, internally displaced persons, and new migrants; individual efficacy; social cohesion and collective action; the extent of trust in community leadership; and political attitudes and beliefs. In addition, the follow-up survey probed attitudes about the CD R program among respondents who lived in treatment communities.

\subsection{Wave III: Behavioral Outcomes}

The final wave of data collection took place between July and September 2008, nearly six months after the CD R program came to an end. To complement the data gleaned from household surveys,

\footnotetext{
${ }^{3}$ The number of surveys conducted in each town or village was roughly proportional to its population size (as estimated by the UN), although we slightly oversampled smaller communities. Households were randomly selected using one of two methods. In smaller communities, all households were numbered and then an interval was generated and a random number was used to determine the initial household. In larger communities, a central point was chosen and the team leader identified four directions. The expected distance in walking time to the end of the settlement was calculated and then an interval determined on the basis of how many households needed to be sampled in each direction. Within households, the household head answered an initial set of questions and then a random individual was sampled from among all eligible adults between the ages of 18 and 60 to respond to the political and social questions.
} 
we implemented a behavioral public goods "game" carried out in the largest village in each of the 83 treatment and control communities. ${ }^{4}$

The behavioral game worked as follows. Initially, an advance team visited each village to announce/ explain the project and to gain the consent of the village leadership. O ne week later, we facilitated a community meeting at which villagers were told the community could receive up to $\$ 400$ to spend on a development project. They were also told that receipt of the funds would depend (a) on whether the community completed a form indicating how the money would be spent and which three people would handle the funds and (b) on how much money a random sample of 24 people contributed to the project in a community-wide public goods game (or n-person prisoner's dilemma in the language of experimental economics). O ne week later, a team returned to the village, collected the form, sampled 24 households, played the public goods game, publicly counted the contributions, and delivered the money to the three community representatives. ${ }^{5}$

The public goods game itself was straightforward: 24 randomly selected individuals (from randomly selected households) were given an opportunity to decide how much of 300LD (approx $\$ 5$ US or a week's wages) they wished to contribute to the community and how much they wanted to keep for themselves. Half of the players had their contributions to the community multiplied by two, and half were multiplied by five. Each community had the opportunity to earn up to 25,200 LD. In addition, we ran a cross-cutting experimental treatment (balanced across CD R treatment status) in which all 24 players were women in half of the communities, while 12 were men and 12 were women in the other half.

There are considerable advantages to the behavioral public goods game as a strategy for measuring the outcomes of CD R. Most importantly, it permits us to observe the means by which communities select representatives and decide on community projects and to measure the actual level of cooperation achieved, based on individual decisions taken by a random sample of households. It also imposes real costs on behavior that reflects a social desirability bias (e.g., "I'll say that I support democracy because I know I should or I know that is what they want to hear") rather than an individual or the community's true beliefs and preferences. Finally, the implementation of the game was entirely disconnected from the CD R program; it was carried out by a Liberian NGO and the implementers did not know which communities received the CD R program and which did not.

The behavioral game was completed successfully in 82 communities. Thus we have data from 1968 individual contribution decisions, along with accompanying survey results on each household that participated. We also gathered detailed information from the chief and the three selected community representatives in each of the 82 communities to permit an analysis of community processes.

\footnotetext{
4 The use of the term "game" here follows from the fact that the approach employed draws on researchers studying

"game theory", a branch of economics that examines the behavior of individuals in strategic settings.

${ }^{5}$ For sampling, all households were numbered and then an interval was generated and a random number was used to determine the initial household. Within households, a random individual was sampled from among all eligible adults between the ages of 18 and 60 to respond to the political and social questions.
} 


\section{Findings from the Survey}

The survey instrument contained nearly 200 questions designed to assess the impact of the CD R program on a wide range of individual and community-level outcomes. In putting together the survey instrument, we drew on a battery of social capital questions developed by the World Bank, standard questions on political attitudes developed by the Afrobarometer, and added new questions that we field-tested in Lofa County before the administration of the survey began.

The data generated through the household surveys are extensive. There are a number of different proxies for each outcome of interest. There are a number of ways of assessing the impact of the program - from a comparison of simple differences in treatment and control outcomes in 2008 to a more complex analysis that looks at the difference in how particular variables have changed over time since 2006. Moreover, the sample size is sufficiently large that responses can be analyzed for particular sub-groups, not just communities as a whole.

This paper reports "first order" results for key proxies that allow us to address the hypotheses described above. We focus on results from the post-survey, however, where possible we also indicate whether the effects are strengthened or weakened when one takes into account the results from the baseline survey by introducing baseline measures as controls or using them for a "difference-in-differences" analysis in which we look for an impact of CD R on the change we observe in particular variables over time.

The tables report the average response to a given question for households in treatment and control communities. They also report the average effect of the IRC program, which is the difference between the average response in treatment and control communities. Finally, they report the standard error of that estimate. ${ }^{6}$

In the analysis presented here we generally do not "control" for features such as the age, gender, or other attributes of respondents or of communities. This is justified by the fact that the randomization procedure guarantees that there are no biases resulting from such features in expectation. As noted above, however, there are some differences between treatment and control areas; to account for these a number of the results have been subjected to robustness tests (not reported here) in which controls have been introduced. Although sometimes important, in general, we find that these controls have a modest effect on the results reported here.

There are very many questions and responses studied in this report, and thus many different results. In the concluding section of the paper, we provide a discussion of how we make an overall assessment of program impact based on all of these different outcomes.

\subsection{Material Welfare}

\subsubsection{Access to Amenities}

We begin our analysis by considering Hypotheses 1.1: access to basic amenities. We do so first by examining physical proximity to amenities such as clinics, schools, water sources and then by

\footnotetext{
${ }^{6}$ For the analyses reported here, standard errors are clustered at the level of communities to take account of the fact that observations are not independent within communities. Note, in addition, that the reported results estimate the sample average treatment effect and not the population average treatment effect.
} 
examining welfare effects in the form of health and education outcomes. In some sense, proximity to services can be thought of as outputs of the CD R program, rather than impacts per se. We know from monitoring by the IRC that local public goods were in fact constructed in treatment communities, community facilities in particular. By including them here, however, our goal is to assess whether treatment communities ended up significantly better off in terms of these outputs than control communities as a consequence of the program.

Table 1: Community Public Goods

\begin{tabular}{lccc}
\hline \hline & $\begin{array}{c}\text { Individuals in control } \\
\text { communities }\end{array}$ & $\begin{array}{c}\text { Individuals in treatment } \\
\text { communities }\end{array}$ & $\begin{array}{c}\text { Difference } \\
\text { (se) }\end{array}$ \\
Outcome & 2.96 & 2.31 & -.65 \\
No. of wells & 1.28 & 1.38 & $.45)$ \\
No. of classrooms & 2.86 & 3.28 & $(.23)$ \\
No. of latrines & .59 & .42 \\
No. of health clinics & .62 & .72 & $(.77)$ \\
No. of comm. facilities & & $.27^{* * *}$ \\
& & & $(.09)$ \\
& & $.14^{*}$ \\
\hline
\end{tabular}

*** Significant at 99\%; ** Significant at 95\%; * Significant at 90\%. The table reports results from a t-test comparing mean outcomes across individuals in control and treatment communities. Standard errors are clustered by community. There are approximately 1500 respondents for each outcome, about evenly divided between treatment and control communities.

Table 1 reports the average number of key local public goods in treatment and control communities. Unsurprisingly, given the emphasis that CD R communities put on the construction of community facilities (including palaver huts and government guesthouses), individuals in treatment communities report higher numbers of local community facilities. ${ }^{7}$ There is also clear evidence that treatment communities have less health clinics - a fact that we believe is related to the observation that treatment villages tend to be more rural and less accessible to the main road (as we reported in our analysis of baseline survey data). Consistent with this not being a causal effect of the program, the difference between treatment and control communities in terms of clinic presence disappears when the 2006 baseline is taken into account. By contrast, the program impact on community facilities is even stronger in that specification.

We can also assess whether access to key services has improved as a function of the CDR program. Table 2 reports the average walking distance (in minutes) to a set of services that contribute to household welfare.

\footnotetext{
${ }^{7}$ Approximately 35\% of community projects were town facilities, such as meeting halls, government guesthouses, market stalls, and warehouses. Another 30\% were VIP latrines designed to improve sanitation. Nearly $15 \%$ were hand dug wells. Very few projects (less than $5 \%$ in total) focused on school or health clinic construction.
} 
Table 2: Distance to Services

\begin{tabular}{lccc}
\hline \hline & $\begin{array}{c}\text { Individuals in control } \\
\text { communities }\end{array}$ & $\begin{array}{c}\text { Individuals in treatment } \\
\text { communities }\end{array}$ & $\begin{array}{c}\text { Difference } \\
\text { (se) }\end{array}$ \\
Outcome & 14.55 & 12.17 & -2.38 \\
Min. walk to water & 97.39 & 104.81 & $(1.81)$ \\
Min. walk to market & 79.00 & 86.82 & $(17.63)$ \\
Min. walk to transport & 32.99 & 30.11 & 7.84 \\
& & & $(18.14)$ \\
Min. walk to pr. school & 52.33 & 52.55 & -2.88 \\
Min. walk to sec. school & 70.40 & $98.49)$ \\
Min. walk to clinic & 7.72 & 6.70 & .22 \\
& & $6.81)$ \\
Min. walk to latrine & & $28.30^{*}$ \\
& & & $(16.07)$ \\
\hline
\end{tabular}

N otes: *** Significant at $99 \%$; ${ }^{* *}$ Significant at $95 \%$; ${ }^{*}$ Significant at $90 \%$. The table reports results from a ttest comparing mean outcomes across individuals in control and treatment communities. Standard errors are clustered by community. There are approximately 1500 respondents for each outcome, about evenly divided between treatment and control communities.

There is no evidence that the CD R program decreased the walking time to key services for households living in treatment communities. Households in CD R areas have to walk longer distances to clinics and also to transport and market (although the latter two are not significant effects) a difference which is likely due to the greater isolation of treatment communities (these differences disappear in a difference in differences specification). In the difference in differences specification, there is some evidence that the time needed to walk to water, markets, secondary schools, and clinics in treatment communities has decreased at a faster rate than in control communities, although only the estimate for secondary schools is significant at conventional levels.

Broadly these results suggest that while the program may have resulted in infrastructural investments, the scale of these investments is not sufficient to produce a major difference in access to amenities and services.

Finally, whereas Table 1 and Table 2 examine the existence of services, Table 3 explores measures that better capture access. Access to services reflects both the availability of functioning services and household level decisions to access these services when they are available. As measures of access, we examine ultimate outcomes in the form of educational attainment and health status. 
Table 3: Health and Education

\begin{tabular}{|c|c|c|c|}
\hline & $\begin{array}{l}\text { Individuals in control } \\
\text { communities } \\
(\mathrm{N})\end{array}$ & $\begin{array}{c}\text { Individuals in treatment } \\
\text { communities } \\
(\mathrm{N})\end{array}$ & $\begin{array}{c}\text { Difference } \\
(\mathrm{se}) \\
\end{array}$ \\
\hline $\begin{array}{l}\text { Probability child ( } 7-20 \text { years old) } \\
\text { is in school }\end{array}$ & $\begin{array}{l}83.4 \% \\
(1559)\end{array}$ & $\begin{array}{l}87.7 \% \\
(1554)\end{array}$ & $\begin{array}{c}+4.3^{* * *} \\
(1.6)\end{array}$ \\
\hline $\begin{array}{l}\text { Probability child ( } 7-20 \text { years old) } \\
\text { has some formal education }\end{array}$ & $\begin{array}{l}85.6 \% \\
(1546)\end{array}$ & $\begin{array}{l}89.4 \% \\
(1551)\end{array}$ & $\begin{array}{l}+4^{* *} \\
(1.8)\end{array}$ \\
\hline $\begin{array}{l}\text { Probability child ( } 5 \text { or under) sick } \\
\text { in last month [mostly fevers] }\end{array}$ & $\begin{array}{l}18 \% \\
(466)\end{array}$ & $\begin{array}{l}24 \% \\
(485)\end{array}$ & $\begin{array}{c}+6 \\
(3.6)\end{array}$ \\
\hline
\end{tabular}

We see from Table 3 that individuals in IRC treatment communities enjoyed greater access to education with a $4.3 \%$ higher attendance rate among children and youths aged 7 to 24 . This difference is significant at the $99 \%$ level; moreover, it is all the more striking because baseline data reveals that access to education was in fact marginally lower in treatment communities than in control communities. Similar results hold when we focus on the probability that a child or youth has had minimal access to education. Further exploration of the data suggests that the gains in treatment communities are strongest among children attending at the secondary level. If there are gains in education, we note, this is likely not due to improved facilities but to the decisions made by households given the facilities available.

Turning to health, Table 3 shows that the incidence of sickness among children aged 5 or below is in fact higher in IRC areas. The $6 \%$ difference in incidence is shy of significance at the $90 \%$ level; moreover, in baseline data, sickness was less common in treatment areas. This finding is the most negative result found in this study; it is, however, in part accounted for by the fact that treatment areas are ex ante more rural and more distant from clinics and clean water sources.

\subsubsection{Livelihoods}

We now consider more household level measures of material welfare. Recall that Hypothesis 1.2 states that CD R programs, by improving local public goods provision, thereby improve income and wealth. Indeed, one of the motivations for launching CD R programs in post-conflict environments is to rapidly channel funds to local communities in order that households see tangible benefits from peace very early on.

We expect that there may be immediate employment gains in the course of a CD R program as a result of activities directly related to CDR. However, here we examine whether employment differences exist after completion of the programs, which would provide evidence for more durable welfare effects. 
Table 4 shows differences in employment rates (defined as being in full time or "consistent part time / contract work" arrangements) among non-student and non-retired individuals aged 1535 , broken down by gender. The table shows that subsequent to the IRC intervention employment rates are no different for male youths; but are 4.9 points higher for female youths. This provides some evidence of positive effects on employment. Moreover this effect is largely unchanged once we control for rurality. Further inspection of the data reveal that the main gains in female employment come from households reporting fewer females as unemployed and not looking for work and more as working within households. This difference could in part reflect different evaluations of domestic labor rather than material gains in income generation; although the latter is not excluded.

Table 4: Employment

\begin{tabular}{|c|c|c|c|}
\hline & $\begin{array}{c}\text { Individuals in control } \\
\text { communities } \\
(\mathrm{N}) \\
\end{array}$ & $\begin{array}{c}\text { Individuals in treatment } \\
\text { communities } \\
(\mathrm{N}) \\
\end{array}$ & $\begin{array}{c}\text { Difference } \\
(\mathrm{se}) \\
\end{array}$ \\
\hline $\begin{array}{l}\text { Probability (non-student) male } \\
\text { youth (15-35 years old) employed }\end{array}$ & $\begin{array}{l}73.3 \% \\
(435)\end{array}$ & $\begin{array}{l}74 \% \\
(377)\end{array}$ & $\begin{array}{c}0.7 \\
(4.7)\end{array}$ \\
\hline $\begin{array}{l}\text { Probability (non-student) female } \\
\text { youth (15-35 years old) employed }\end{array}$ & $\begin{array}{c}85.1 \% \\
(632)\end{array}$ & $\begin{array}{l}90 \% \\
(582)\end{array}$ & $\begin{array}{l}4.9 * * \\
(1.4)\end{array}$ \\
\hline
\end{tabular}

Finally, we examine asset ownership. The survey instrument queried respondents on their ownership of key assets including livestock, chickens and guinea fowl, and household wares. The survey also asked about patterns of rice planting - the dominant form of agriculture in the region and the regularity with which households are cooking meals.

Table 5 reports estimates of the average effect of the IRC program on total asset ownership, on rice planting, and on meals. In addition, we show the estimated effect of the IRC program on per-adult ownership of asset and planting. There is some evidence of a positive impact of the program, especially on the ownership of chickens, with households in treatment communities owning on average nearly 2 additional chickens. The impacts on rice planting and the number of meals cooked the previous day are also close to conventional levels of significance. In the case of rice planting, the gain corresponds to a $12 \%$ gain in production. Most other effects are neither sizeable nor significant. If we examine per capita holdings, we find similar results, with effect sizes typically gaining in significance somewhat and suggesting gains in rice planting and fowl ownership as well as chicken ownership.

These findings suggest that there may be some modest benefits to communities in terms of small asset holdings. ${ }^{8}$

\footnotetext{
8 In the presence of multiple outcomes, one should be cautious in placing too much confidence on estimated effects in just one or two measures. We note, however, that the estimated effect on chicken holdings, and in particular chickens per household member, can also be observed in an independent sample of almost 2000 subjects participating in the behavioral games. Moreover, while for both datasets the effect is weakened when we control for urban residence, the effect size of chickens per adult remains significant at the $95 \%$ level.
} 
Table 5: Asset Ownership, Planting, and Meals

\begin{tabular}{|c|c|c|c|}
\hline Outcome & $\begin{array}{l}\text { Households in control } \\
\text { communities }\end{array}$ & $\begin{array}{c}\text { Households in treatment } \\
\text { communities }\end{array}$ & $\begin{array}{l}\text { Difference in household } \\
\text { assets } \\
\text { (se) }\end{array}$ \\
\hline Tins of rice planted & 3.41 & 3.81 & $\begin{array}{c}.40 \\
(.24)\end{array}$ \\
\hline No. of meals yesterday & 1.26 & 1.31 & $\begin{array}{c}.05 \\
(.03)\end{array}$ \\
\hline No. of rooms & 3.25 & 3.42 & $\begin{array}{l}.16 \\
(.12)\end{array}$ \\
\hline No. of sheep or goats & .22 & .19 & $\begin{array}{l}-.03 \\
(.06)\end{array}$ \\
\hline No. of chickens & 5.36 & 7.04 & $\begin{array}{c}1.68^{* * *} \\
(.69)\end{array}$ \\
\hline No. of guinea fowl & .09 & .16 & $\begin{array}{l}.07 \\
(.05)\end{array}$ \\
\hline No. of bamboo beds & 2.31 & 2.46 & $\begin{array}{l}.15 \\
(.15)\end{array}$ \\
\hline No. of wooden beds & .34 & .29 & $\begin{array}{l}-.05 \\
(.07)\end{array}$ \\
\hline No. of foam mattresses & .49 & .52 & $\begin{array}{l}.03 \\
(.09)\end{array}$ \\
\hline No. of straw mattresses & 2.23 & 2.23 & $\begin{array}{l}-.00 \\
(.13)\end{array}$ \\
\hline No. of buckets & 1.89 & 1.85 & $\begin{array}{l}-.04 \\
(.10)\end{array}$ \\
\hline No. of fitted doors & 2.44 & 2.43 & $\begin{array}{l}-.00 \\
(.22)\end{array}$ \\
\hline No. of radios & .40 & .45 & $\begin{array}{l}.05 \\
. .04)\end{array}$ \\
\hline
\end{tabular}

*** Significant at 99\%; ${ }^{* *}$ Significant at 95\%; * Significant at 90\%. The table reports results from a t-test comparing mean outcomes across individuals in control and treatment communities. Standard errors are clustered by community. There are approximately 1500 respondents for each outcome, about evenly divided between treatment and control communities.

However, we note that the inter-temporal analysis does not strengthen confidence in these findings. We have two ways of looking at change over time in these measures of asset ownership. First, we can assess change using our 2008 respondents' recollections of asset ownership in 2006 as the baseline. Second, we can compute change with responses from 2006 as a baseline (although responses in 2006 were gathered from the household head, while in 2008 a randomly selected household member provided the response). Using the first approach, we find generally weaker evidence for a positive effect of the program; under the second approach, we find more positive evidence but for a different set of assets. The instability of our estimates using this historical data suggests that asset ownership was likely measured with significant error and that the results on small assets should be treated with caution. 


\subsection{Govemance}

\subsubsection{Attitudes about Govemance}

An explicit goal of $\mathrm{CDR}$ is to expose individuals to the practice of democratic, transparent, and accountable governance. Hypothesis 2.1 suggests that this exposure will lead to greater support for more democratic forms of government. To examine this hypothesis, we asked respondents to give their opinion on a range of potentially divisive issues related to decision-making in their communities. The results are reported in Table 6.

Table 6: Support for Democracy

\begin{tabular}{|c|c|c|c|}
\hline Outcome & $\begin{array}{l}\text { Individuals in control } \\
\text { communities }\end{array}$ & $\begin{array}{l}\text { Individuals in treatment } \\
\text { communities }\end{array}$ & $\begin{array}{c}\text { Difference } \\
\text { (se) } \\
\end{array}$ \\
\hline $\begin{array}{l}\text { Share agreeing that people should be } \\
\text { more active in questioning leaders }\end{array}$ & .72 & .75 & $\begin{array}{l}.03 \\
(.03)\end{array}$ \\
\hline $\begin{array}{l}\text { Share agreeing that leaders should not } \\
\text { favor their own ethnic group }\end{array}$ & .90 & .92 & $\begin{array}{l}.02 \\
.02)\end{array}$ \\
\hline $\begin{array}{l}\text { Share agreeing that all should be } \\
\text { permitted to take part in decisions }\end{array}$ & .60 & .58 & $\begin{array}{l}-.02 \\
(.03)\end{array}$ \\
\hline $\begin{array}{l}\text { Share agreeing that women should have } \\
\text { equal rights }\end{array}$ & .79 & .80 & $\begin{array}{l}.01 \\
(.02)\end{array}$ \\
\hline $\begin{array}{l}\text { Share agreeing that leaders should be } \\
\text { chosen through elections }\end{array}$ & .82 & .86 & $\begin{array}{l}.04 \\
(.03)\end{array}$ \\
\hline $\begin{array}{l}\text { Share agreeing that community } \\
\text { members have the responsibility for } \\
\text { improving things in the town }\end{array}$ & .63 & .67 & $\begin{array}{l}.05^{*} \\
(.03)\end{array}$ \\
\hline \multicolumn{4}{|c|}{$\begin{array}{l}\text { *** Significant at } 99 \% \text {; ** Significant at } 95 \% \text {; } * \text { Significant at } 90 \% \text {. The table reports results from a t-test comparing } \\
\text { mean outcomes across individuals in control and treatment communities. Standard errors are clustered by community. } \\
\text { There are approximately } 1500 \text { respondents for each outcome, about evenly divided between treatment and control } \\
\text { communities. }\end{array}$} \\
\hline \multicolumn{4}{|c|}{$\begin{array}{l}\text { We find only weak support for the idea that exposure to CD R increases support for } \\
\text { democratic practices. On most issues, respondents in treatment communities are more likely to } \\
\text { support the more democratic propositions than those in control communities, although the effects } \\
\text { are very small and often not significant. Individuals in treatment communities are more likely to } \\
\text { agree that people should question their leaders; that leaders should pursue the public interest, rather } \\
\text { than the interests of their family or ethnic group; that leaders should be chosen through elections; } \\
\text { and that community members (not the government) bear the primary responsibility for improving } \\
\text { things in the town. Only this last result is statistically significant and then only at the } 90 \% \text { level. This } \\
\text { result, however, does not hold up in a difference-in-differences specification which takes account of } \\
\text { how respondents answered these same questions two years earlier. }\end{array}$} \\
\hline
\end{tabular}




\subsubsection{Attitudes of Leaders}

To address Hypotheses 2.2, in addition to examining changes in attitudes of citizens in the project areas, we also examined whether the program has an impact on the attitudes of leaders. By engaging in the participatory and democratic forms of decision-making employed in the CD R process, do leaders alter their positions to be more welcoming of broad based approaches and more appreciative of the contributions of non-elites to decision making?

To answer the question, we interviewed village chiefs in all of the hub towns of the treatment and control CDC areas (i.e. the largest village of the community) as well as a random sample of chiefs in other town. We asked them to describe their attitudes on a range of questions associated with who should take part in decisions and to whom leaders should be accountable. The results are shown for six questions in Table 7. The table reports the degree to which chiefs in treatment (black circles) and control areas (white circles) agree with more or less inclusive or democratic positions with respect to decision making.

Table 7: Village Chief Attitudes to Decision-making

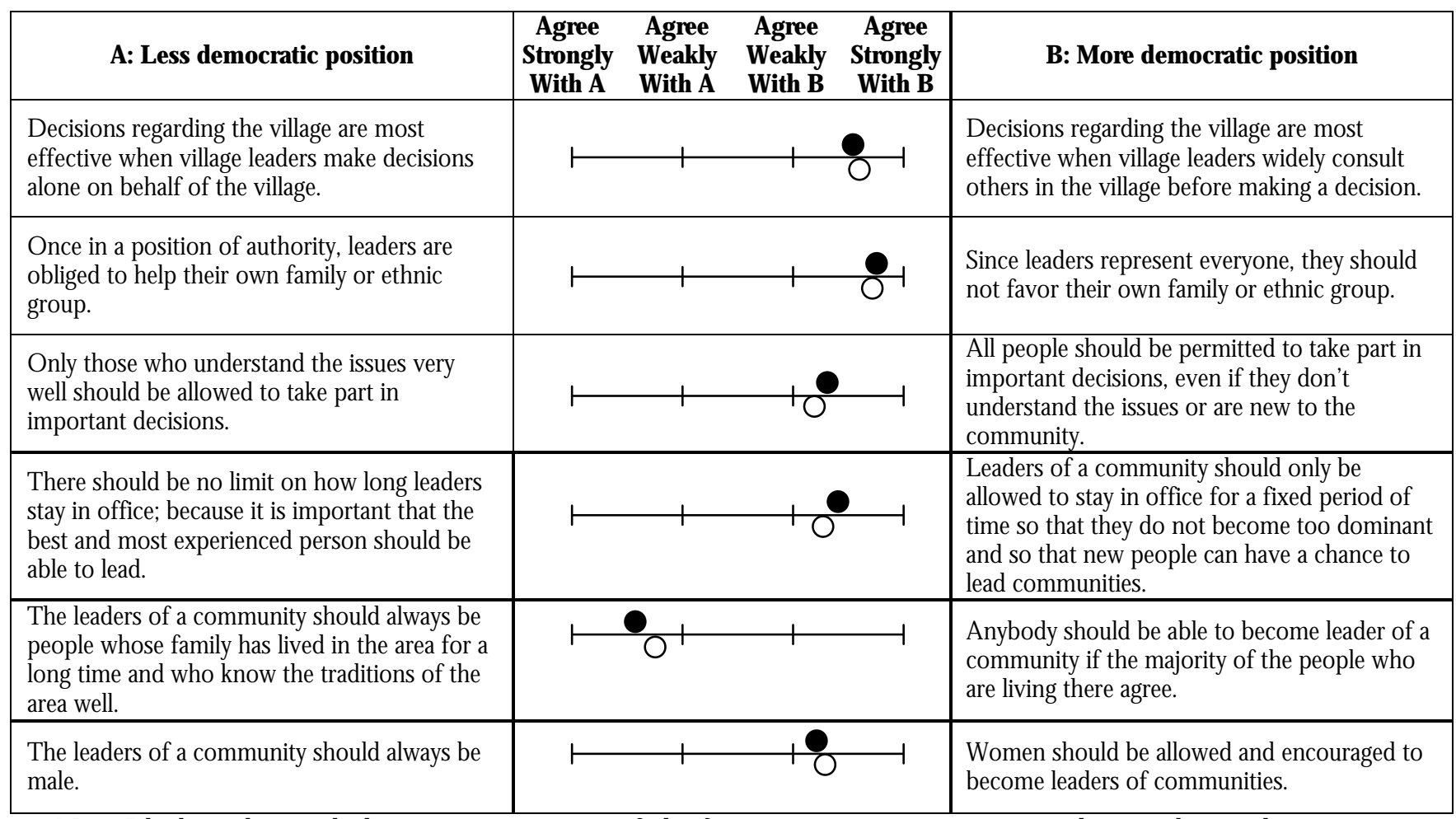

N otes: Black circles mark the average response of chiefs in treatment communities; white circles mark average responses in control communities. In no case are these differences statistically significant.

Table 7 provides no evidence of an effect of the IRC program on the self-reported attitudes of leaders. Across all measures, the average response given by chiefs in treatment communities is indistinguishable from that given in control communities.

This is a negative finding for the program. But there is another finding that can be seen from Table 7 that is just as important: across all but one measure, the positions of leaders are strongly supportive of inclusive approaches in both treatment and control areas. An implication is that the 
problem may not so much lie in the effectiveness of the program but in its background assumption: that attitudes to decision-making were not inclusive at the outset.

\subsubsection{Individual Efficacy}

Hypothesis 2.3 suggests that participatory CD R programs provide individuals with self-confidence and increase their sense of personal efficacy. We collected a variety of measures of individual efficacy, focusing both on individual's beliefs and their actions.

Table 8: Individual Efficacy

\begin{tabular}{lccc}
\hline \hline & $\begin{array}{c}\text { Individuals in control } \\
\text { communities }\end{array}$ & $\begin{array}{c}\text { Individuals in treatment } \\
\text { communities }\end{array}$ & $\begin{array}{c}\text { Difference } \\
\text { (se) }\end{array}$ \\
\hline $\begin{array}{l}\text { Beliefs } \\
\text { Share agreeing that "an ordinary person can } \\
\text { influence decisions about community affairs" }\end{array}$ & .62 & .56 & $\begin{array}{c}-.06 \\
.05)\end{array}$ \\
\hline $\begin{array}{l}\text { Share agreeing that they are "influential" in } \\
\text { decision-making }\end{array}$ & .21 & .24 & .03 \\
\hline $\begin{array}{l}\text { Share claiming to be satisfied overall "with the way } \\
\text { that decisions that affect all community members } \\
\text { are made" in the town }\end{array}$ & .66 & .67 & .01 \\
\hline Actions & & & $(.04)$ \\
\hline Attended a town meeting & & .84 & .03 \\
\hline Made a speech & .80 & .03 & $(.03)$ \\
\hline Met with chief & .59 & .04 \\
& & $.03)$ \\
\hline Notified police & .42 & .08 & .05 \\
\hline Met with a government official & .09 & $.04)$ \\
\hline
\end{tabular}

Intentions...

\begin{tabular}{lccc}
\hline Work in the next election & .71 & .77 & $\begin{array}{c}.06^{*} \\
(.03)\end{array}$ \\
\hline Vote in the next election & .95 & .97 & $.02^{*}$ \\
& & & $(.01)$ \\
\hline
\end{tabular}

*** Significant at $99 \%$; ** Significant at $95 \%$; Significant at $90 \%$. The table reports results from a t-test comparing mean outcomes across individuals in control and treatment communities. Standard errors are clustered by community. There are approximately 1500 respondents for each outcome, about evenly divided between treatment and control communities.

Table 8 presents estimates of the impact of the CD R program on individual efficacy. There is not much evidence that CD R has changed how individuals think about how much they can influence community affairs. There is slightly more evidence that CD R has increased the level of activism of individuals in communities that received the program, although these effects are always small, and only significant in the case of people's plans to work on and vote in the next election. A gain we note that for those issues in which there is some evidence of a positive effect, baseline measures are already very high. When we examine responses in 2008, in light of how individuals 
answered the same questions in 2006, there is still no consistent evidence of a CD R program impact in this area. ${ }^{9}$

\subsubsection{Trust in Community Decision Making Procedures}

Hypothesis 2.4 suggests that CD R programs enhance people's trust in their community decision making procedures, perhaps by setting in place new expectations about how community processes should be run or by creating formal structures that empower community members which persist after the program's conclusion.

Table 9: Trust in Leadership

\begin{tabular}{|c|c|c|c|}
\hline Outcome & $\begin{array}{l}\text { Individuals in control } \\
\text { communities }\end{array}$ & $\begin{array}{l}\text { Individuals in treatment } \\
\text { communities }\end{array}$ & $\begin{array}{c}\text { Difference } \\
\text { (se) }\end{array}$ \\
\hline \multicolumn{4}{|l|}{ A ctions } \\
\hline Village meetings held in past year? & .82 & .87 & $\begin{array}{c}.05 \\
(.03)\end{array}$ \\
\hline Number of meetings in past six months & 6.34 & 6.36 & $\begin{array}{l}.00) \\
.02 \\
.71)\end{array}$ \\
\hline \multicolumn{4}{|l|}{ Beliefs } \\
\hline $\begin{array}{l}\text { Share saying that appealing to a village/ town } \\
\text { chief can help with local problems }\end{array}$ & .90 & .95 & $\begin{array}{l}.05 * * * \\
(.02)\end{array}$ \\
\hline $\begin{array}{l}\text { Share saying that town leaders are more or } \\
\text { much more trustworthy than in neighboring } \\
\text { towns }\end{array}$ & .47 & .59 & $\begin{array}{c}.12 * * * \\
(.04)\end{array}$ \\
\hline $\begin{array}{l}\text { Share saying that town leaders are more or } \\
\text { much more trustworthy than in other parts of } \\
\text { Lofa County }\end{array}$ & .39 & .47 & $\begin{array}{c}.09 * * * \\
(.04)\end{array}$ \\
\hline $\begin{array}{l}\text { Share saying that community leaders would not } \\
\text { keep any funds for private use }\end{array}$ & .44 & .51 & $\begin{array}{c}.07 * * * \\
(.03)\end{array}$ \\
\hline $\begin{array}{l}\text { If the town received } \$ 10,000 \text {, what share } \\
\text { should be given directly to community } \\
\text { members instead of community leaders? }\end{array}$ & $34 \%$ & $35 \%$ & $\begin{array}{l}1 \% \\
(85)\end{array}$ \\
\hline
\end{tabular}

N otes:*** Significant at 99\%; ${ }^{* *}$ Significant at $95 \%$; ${ }^{*}$ Significant at $90 \%$. The table reports results from a t-test comparing mean outcomes across individuals in control and treatment communities. Standard errors are clustered by community. There are approximately 1500 respondents for each outcome, about evenly divided between treatment and control communities.

Table 9 presents estimates of how the CD R program affected reported levels of trust in community leadership. Consistently, respondents report higher levels of faith in the trustworthiness of leaders in communities that experienced CD R as opposed to control communities. Respondents in places that were exposed to CD R express more faith in the ability of town chiefs to resolve local

\footnotetext{
${ }^{9}$ In the appendix we show that there is imbalance on previous voting behavior between treatment and control in the baseline survey. Accounting for past voting however has a negligible effect on the effect estimated in Table 9 however, resulting in a decline from 0.2 to 0.19 ; however with few observations in this specification, the associated $p$-value rises to 0.13. Controlling for past involvement in an election campaign in fact increases the estimated treatment effect by 2 points and reduces the p-value to 0.02 .
} 
problems; believe town leaders are more trustworthy than those in neighboring towns and areas; and believe strongly that their own leaders, if given funds to spend on the community, would not keep any money for their private use. They do not however report an increased willingness to place funds under the control of community leadership. The results are strongly significant and the magnitude is substantial, with CD R increasing the share of community members reporting faith in their leaders by between 5 and 12 percentage points depending on the measure.

\subsection{Social Cohesion}

One major motivation for the participatory processes embedded in the CD R program is the possibility that successful community mobilization can help to ease tensions between groups and lead to more successful collective action in the future. This is especially relevant in post-conflict contexts where the conflict may have generated tensions within a village.

\subsubsection{Social Acceptance}

To examine Hypothesis 3.1, we generated a standard version of a social distance scale, asking about a respondent's comfort level with particular groups as members of the community, as landowners in the village, as leaders of the community, as close friends, and as kin by marriage. We focus our attention on how households think about three marginalized groups in particular: returnees from conflict displacement, new migrants to the area (often as a result of conflict), and ex-combatants.

Table 10: Social Inclusion

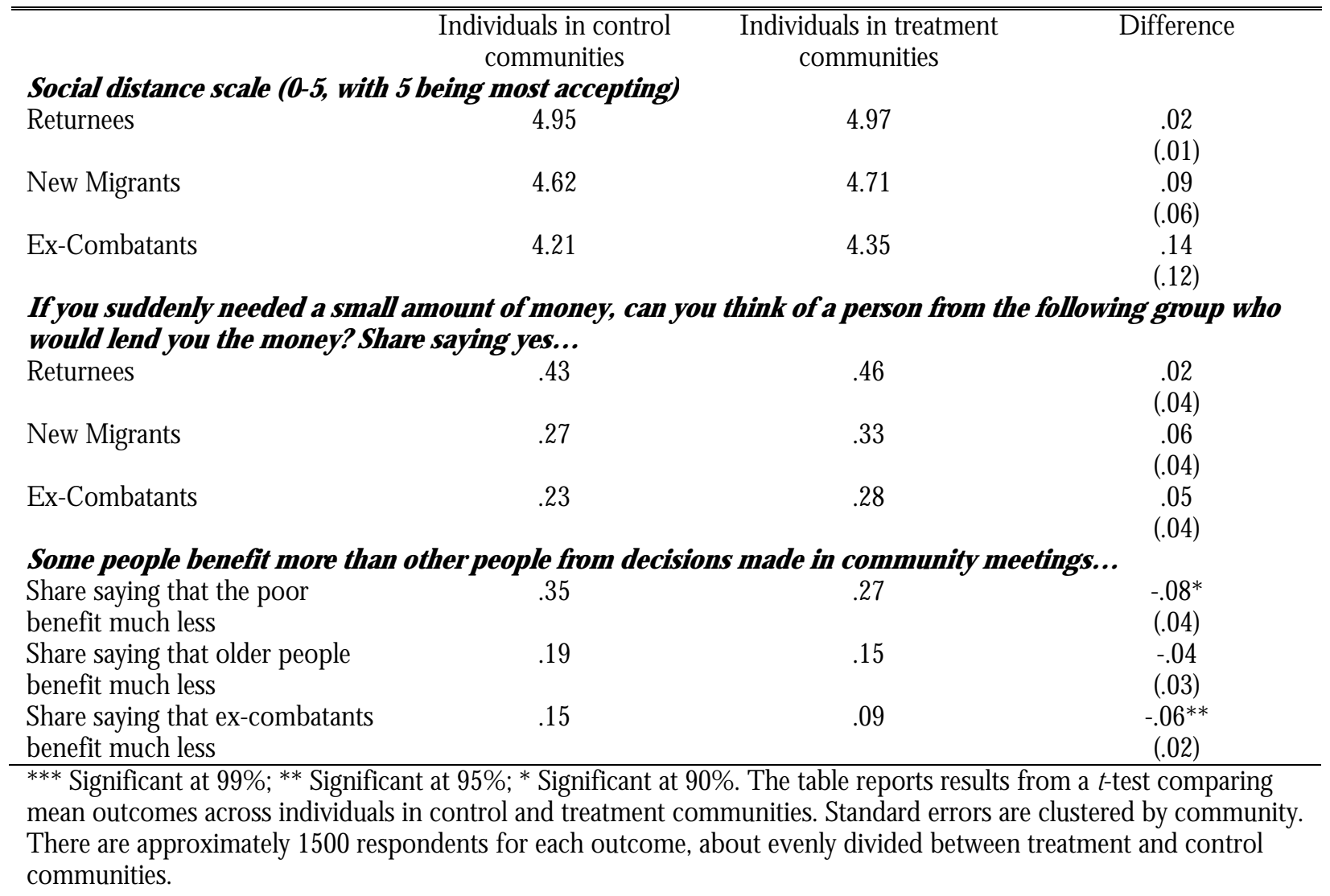


As one can see in the first three rows of Table 10, expressed levels of comfort with these three groups are high in both treatment and control communities. 5 is the maximum score than can be achieved, indicating a respondent's willingness to accept a member of the specified group in any of the roles mentioned above and in most cases responses are close to this ceiling. Even with acceptance very high overall, respondents in CD R communities exhibit higher levels of acceptance of new migrants and ex-combatants, although these results fall just below conventional levels of statistical significance. O ther measures that asked about people being refused access to services also indicate that there are high levels of acceptance of different types of individuals in all communities.

We also posed hypothetical questions about the types of situations individuals might encounter in their daily life. For example, if someone needed a small amount of money as a loan to meet household expenses, would they be able to find someone from a particular group who could assist them? We use this question - and one focused on whether people could identify someone to take care of their children - to gauge the extent to which returnees, new migrants, and excombatants have been reinserted into the social fabric of the community.

The results in Table 10 suggest that households in communities exposed to CD R are somewhat more likely to be able to think of returnees, new migrants, and ex-combatants who would be willing to lend them money, than households in control communities. These results again are just below conventional levels of significance. The findings are almost identical (and in fact a bit stronger) for the question related to taking care of one's children.

A final strategy we pursue is to ask about the way in which different groups are treated in the context of community decision-making processes. Recognizing that some groups benefit more than others from community meetings, we ask respondents to tell us the extent to which the interests of the poor, older generations, and ex-combatants are reflected in the outcomes of community meetings. Consistently, many individuals (though always short of a majority) report that these groups benefit much less than others from community processes; but it is clear from the final three rows of Table 10 , that these three groups are not perceived to do as poorly in CD R communities as in those in the control group, with two of the three findings significant at conventional levels. ${ }^{10}$

\subsubsection{Social Tensions}

To examine Hypothesis 3.2, we explore the extent to which social conflict persists in villages in Northern Liberia. Table 11 reports measures of how respondents described the level of social tension that exists in their village.

It is striking that on every measure, respondents in communities exposed to the CD R program report lower levels of tension than individuals from communities in the control group. While in most cases, the difference in the incidence of tensions is small, respondents report that these tensions are less likely to escalate in treatment areas. A number of these findings also pass the conventional bar for statistical significance, with respondents reporting less tension between men and women, and lower levels of violent conflict among genders, between new migrants and community members, and among tribes. Of course, it bears mention that reported levels of tension

\footnotetext{
${ }^{10}$ Although we do not address it here the survey data can be used to measure the extent to which these views are consistent with those held by the marginalized views themselves.
} 
are very low overall; nonetheless, the CD R program seems to have further mitigated tension in those communities that benefitted from the program.

Table 11: Social Tensions

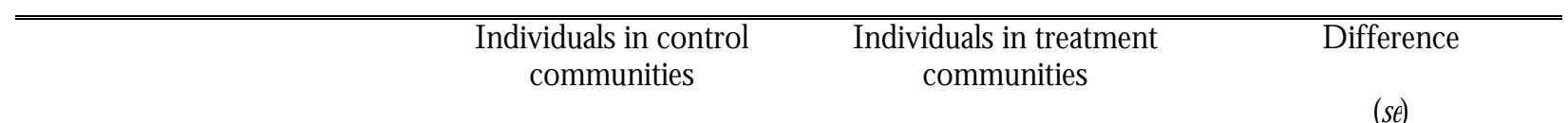

\begin{tabular}{|c|c|c|c|}
\hline To what extent do the foll & ences & n your & gg ver \\
\hline Between rich and poor & 1.28 & 1.22 & $\begin{array}{l}-.06 \\
(.04)\end{array}$ \\
\hline Between men and women & 1.40 & 1.32 & $\begin{aligned}-.08 * \\
(.05)\end{aligned}$ \\
\hline $\begin{array}{l}\text { Between younger and older } \\
\text { generations }\end{array}$ & 1.28 & 1.23 & $\begin{array}{l}-.04 \\
(.03)\end{array}$ \\
\hline $\begin{array}{l}\text { Between new migrants and } \\
\text { community members }\end{array}$ & 1.24 & 1.21 & $\begin{array}{l}-.04 \\
(.04)\end{array}$ \\
\hline Among religions & 1.29 & 1.25 & $\begin{array}{l}-.04 \\
(.05)\end{array}$ \\
\hline Among tribes & 1.28 & 1.22 & $\begin{array}{l}-.06 \\
(.05)\end{array}$ \\
\hline $\begin{array}{l}\text { Among people of different } \\
\text { education }\end{array}$ & 1.19 & 1.17 & $\begin{array}{l}-.02 \\
(.03)\end{array}$ \\
\hline
\end{tabular}

In the past six months, have these differences escalated into violence (1-3, with 3 being often)

Between rich and poor

1.08

$-.02$

Between men and women

1.27

1.20

Between younger and older

1.12

1.10

$-.07 *$

generations

1.08

Between new migrants and

1.08

$-.03$

community members

1.15

$-.05^{* *}$

Among religions

1.10

Among tribes

1.07

1.04

$-.03$

$-.08 *$

Among people of different education

N otes: *** Significant at $99 \%$;* Significant at $95 \%$; $*$ Significant at $90 \%$. The table reports results from a t-test comparing mean outcomes across individuals in control and treatment communities. Standard errors are clustered by community. There are approximately 1300-1500 respondents for each outcome, about evenly divided between treatment and control communities.

These findings are reinforced by results in our survey of town and village chiefs; on these identical questions, chiefs report lower levels of tension in communities exposed to the CD R program. But when initial answers to these questions from 2006 are taken into account in a difference-in-differences set-up, there are no longer significant effects, although treatment communities generally experience a greater reduction in tension than control communities. 


\subsubsection{Collective Efficacy}

In seeking to ease tensions among groups, the hope is that CD R can improve the ability of communities to act collectively. We now turn to measures designed to capture collective efficacy, from the perspective of residents but also as reflected in their actions.

Table 12: Collective Efficacy

\begin{tabular}{|c|c|c|c|}
\hline & $\begin{array}{l}\text { Individuals in control } \\
\text { communities }\end{array}$ & $\begin{array}{c}\text { Individuals in treatment } \\
\text { communities }\end{array}$ & $\begin{array}{c}\text { Difference } \\
\text { (se) }\end{array}$ \\
\hline \multicolumn{4}{|l|}{ Beliefs } \\
\hline $\begin{array}{l}\text { Share agreeing strongly that "people in this town } \\
\text { are willing to cooperate to improve things for the } \\
\text { community" }\end{array}$ & .66 & .62 & $\begin{array}{l}-.04 \\
(.03)\end{array}$ \\
\hline $\begin{array}{l}\text { Share not agreeing that the "town needs strong } \\
\text { leadership from government because people here } \\
\text { are not able to organize to do things" }\end{array}$ & .60 & .70 & $\begin{array}{c}.09 * * * \\
(.03)\end{array}$ \\
\hline \multicolumn{4}{|l|}{$\begin{array}{l}\text { Actions } \\
\text { Share reporting that in the past six month there has been } \\
\text { a community initiative to... }\end{array}$} \\
\hline Rebuild a school or clinic & .26 & .22 & $\begin{array}{l}-.03 \\
(.03)\end{array}$ \\
\hline O rganize roadbrushing & .52 & .55 & $\begin{array}{l}.03 \\
(.05)\end{array}$ \\
\hline Regrade a local road & .20 & .24 & $\begin{array}{l}.04 \\
(.03)\end{array}$ \\
\hline Dig or repair a well & .20 & .17 & $\begin{array}{l}-.03 \\
(.03)\end{array}$ \\
\hline O rganize security & .12 & .11 & $\begin{array}{l}-.01 \\
(.02)\end{array}$ \\
\hline Improve agriculture & .32 & .28 & $\begin{array}{l}-.04 \\
(.04)\end{array}$ \\
\hline Rebuild a church/ mosque & .23 & .23 & $\begin{array}{l}-.01 \\
(.03)\end{array}$ \\
\hline
\end{tabular}

N otes: *** Significant at $99 \%$; ${ }^{* *}$ Significant at $95 \%$; $*$ Significant at $90 \%$. The table reports results from a t-test comparing mean outcomes across individuals in control and treatment communities. Standard errors are clustered by community. There are approximately 1500 respondents for each outcome, about evenly divided between treatment and control communities.

Table 12 presents estimates of the impact of CD R on a variety of measures of collective efficacy. We examine first how respondents describe the collective action potential of their communities. While individuals that experienced CD R are no more likely to report that their neighbors are willing to work together to improve things in the town, they are significantly more likely to believe that the town can achieve things on its own without strong leadership from government.

The remainder of the table emphasizes measures of reported instances of successful collective action. Although the evidence that CD R eased social tensions is reasonably strong, there is relatively little evidence of greater levels of community action. While village meetings were slightly more likely to be held in CD R communities (perhaps as a direct output of the CD R program), there is no 
consistent evidence that CD R communities were more likely to launch community efforts to improve local public goods. The results are very similar in a difference-in-differences analysis. Moreover, in results not reported here, levels of associational life are almost identical in CD R treatment and control communities, suggesting that the program itself does not lead to the sprouting of new organized associations.

\section{Findings on Behavioral Outcomes}

To complement our survey-based measures of social cohesion and approaches to decision making, we sought direct measures of behavioral effects of the CD R program as revealed by behavior in "public goods games." The public goods games were conducted in the largest village associated with each treatment and control community. The behavioral measures generated using this approach were not collected in coordination with IRC and did not employ IRC or D FID funding at any stage; nevertheless, the randomization approach employed by IRC remained essential for allowing us to draw inferences from behavior in these exercises.

In total, 82 communities successfully completed the behavioral game, meaning that they selected three community representatives, identified a set of projects on which the money would be spent, and played a community-wide public goods game. In one community, the game was halted as a result of a rule violation.

To review, the public goods game worked as follows: In the hub town of each of the 83 IRC communities, individuals were selected at random from 24 randomly selected households, given 300 Liberian dollars in 100LD notes, and asked to decide (in private) how much to put into an envelope to be given to the community, and how much to keep for themselves or their family. After the decision, we asked each player a short set of survey questions about his or her knowledge of community meetings held to discuss how the money would be spent, who the community representatives were, beliefs about how others would play the game, and so on. A community meeting was called after all the surveys were finished, at which point the envelopes were opened and the money counted out.

In addition to the main comparison between communities that received and did not receive an IRC CD R program, we also implemented two other experimental treatments in the play of the game. First, in the interest rate treatment, twelve individuals in each community knew that any money they contributed would be doubled by us when given to the community; the other twelve knew that any money they gave would be increased by us by a factor of five. These correspond to interest rates of $100 \%$ and $400 \%$ respectively. Second, for the gender treatment, in about half of the 83 communities, we told the community in advance that only women would be chosen to play the game, while in the other half we told the community that the game would be played by both men and women (and in those "mixed" communities we chose exactly 12 men and 12 women to play).

The main advantage of the public goods game is that it captures behavioral outcomes. It puts us in a position to observe how communities conduct themselves when they confront major decisions and to what extent they are able to mobilize participation from community members. Moreover, because the public goods game was conducted nearly six months after the CD R program came to an end, it offers some evidence of the extent to which the effects we observe as short-term, largely attitudinal changes (in the panel survey) persist and actually shape subsequent behavior. 


\subsection{Social Cohesion}

First, we examine data regarding the contribution levels we observed in communities during the public goods game. These measure individuals' willingness to contribute community public goods, and thus can be viewed as a behavioral measure of social cohesion.

The average payout to villages was 20,022LD and the median received was slightly higher at 20,850LD (out of total possible earnings of 25,200LD). Among individuals, nearly two thirds contributed the maximum amount (300LD). Only 10\% kept the endowment in its entirety. It is worth noting that these contribution rates are impressively high, especially in light of the assumption that Northern Liberia had significant intra-community tensions - which guided the design of the program.

Table 13: Behavioral Measures of Social Cohesion

\begin{tabular}{lccc}
\hline \hline & Control communities & Treatment communities & Difference \\
Outcome & $(\mathrm{N})$ & $(\mathrm{N})$ & $+6.5^{* *}$ \\
\hline Share of available & $75.9 \%$ & $82.5 \%$ & $(2.6)$ \\
funds earned & $(41)$ & $(41)$ & $+5.7^{* *}$ \\
\hline Average share of & $75.1 \%$ & $80.8 \%$ & $(2.6)$ \\
300LD contributed & $(41)$ & $(41)$ & $+9.1^{* *}$ \\
\hline Share contributing & $62.3 \%$ & $71.3 \%$ & $(3.7)$ \\
full amount & $(41)$ & $(41)$ & \\
\hline
\end{tabular}

N otes: *** Significant at 99\%; ** Significant at $95 \%$; ${ }^{*}$ Significant at $90 \%$. The table reports the average treatment effect on the treated, with matching according to assignment to the gender composition treatment; standard errors allow for heteroskedasticity across strata. Results are reported for village level outcomes.

Table 13 presents estimates of the impact of the CD R program on contributions in the public goods game. The first row shows the share of the total available funding earned, the second the average share of 300LD contributed by community members, and the third the share of individuals contributing the full amount. The final column reports average treatment effects estimated by taking a weighted average of the differences in outcomes between treated and untreated units in the women only and in the mixed gender sites. (Recall that in about half of the communities, the contribution game was played by 12 men and 12 women, while in the other half all 24 were women. $)^{11}$

We see that exposure to the CDR program led to an average 6.5 percentage point (or 7.5\%) gain in the share of available funds earned by the community; the average share of the 300LD contributed by households increased by an estimated 5.7 percentage points (7.6\%); and the share of households contributing the full amount increased by 9 percentage points (15\%). These effects are each significant at the $95 \%$ level.

We can get some sense of the magnitude of the effect by examining how players responded to different interest rates. Q uantitatively, the 5.7 point effect of the CDR treatment on individual contributions is about the same as the effect of a change in the social rate of return of an individual's

\footnotetext{
11 We report the average treatment effect on the treated here, matching on gender treatment because of a slight lack of balance in its assignment. Results from the simple average treatment effect, or a t test on the difference of means without matching, yield very similar results.
} 
investment from $100 \%$ to $400 \%$. This change in interest rates yields an estimated 5.8 percentage point change in individual contributions, an effect significant at the $99 \%$ level. ${ }^{12}$ In short, the impact of the CD R program on contribution rates is equivalent (in magnitude) to a substantial increase in the rate of return on people's investments in community-wide public goods.

As noted above, in half of the areas the behavioral game was played with mixed gender groups and in half it was played with women only groups. O ne can think of this cross-cutting gender treatment as producing two distinct measures of the treatment effect. As seen in Table 13, the average program effect across both measures is positive. Table 14, however, reveals that this overall effect masks the fact that the treatment effect differs across these two settings. For mixed gender groups, the treatment effect is substantially stronger than indicated in Table 13. In women's only groups, however, there is no evidence of a program effect. It can be noted, moreover, that contributions in women's only (control) groups are substantially higher than those for mixed groups. Thus, the impact of the intervention appears stronger in helping groups to resolve some sorts of problems than for others; moreover, the effect of the program for mixed groups can be considered to be quantitatively similar to the gains achieved from moving from a heterogeneous group (in terms of gender) to a homogeneous group.

Table 14: CDR Program Impact, by Gender Composition

\begin{tabular}{lccc}
\hline \hline & Control communities & Treatment communities & $\begin{array}{c}\text { Difference } \\
\text { (se) }\end{array}$ \\
\hline Mixed Gender & $66.8 \%$ & $81.2 \%$ & $14.3^{* * *}$ \\
& & & $(3.9)$ \\
\hline Women Only & $84.6 \%$ & $80.3 \%$ & -4.3 \\
& & & $(3.2)$ \\
\hline Difference & $17.7^{* * *}$ & -0.8 & $-18.6^{* * *}$ \\
(se) & $(3.6)$ & $(3.5)$ & $(5.0)$ \\
\hline
\end{tabular}

Notes: *** Significant at 99\%; ** Significant at 95\%; Notes: * Significant at 90\%. Average share of contributions made across subjects. The difference-in-difference estimate is the coefficient on the interaction term from an OLS regression. Results are reported for village level outcomes, for 41 treatment and 41 control communities.

\subsection{Contributions by Socially Marginalized Groups}

While we observe higher levels of social cooperation in communities exposed to the CD R program, a specific goal of the program was to ensure the inclusion of traditionally underrepresented or alienated groups in community processes. As such, it makes sense to ask whether the CD R program increases the contribution rates of marginalized groups or simply strengthens the cooperative capacity of individuals already engaged in community life.

\footnotetext{
12 These estimates are calculated by examining differences between contributions by individuals facing a high and a low interest rate within villages under the assumption that behavior is not strongly sensitive to the composition of interest rates facing other players. For this analysis, standard errors are clustered at the community level.
} 
Table 15: Average Treatment Effect by Subgroup

\begin{tabular}{lc}
\hline \hline & $\begin{array}{c}\text { Effect } \\
(\mathrm{se})\end{array}$ \\
\hline Individuals who identify as internally displaced persons & $0.15^{* * *}$ \\
& $(0.05)$ \\
Ex-combatants & 0.11 \\
& $(0.09)$ \\
Individuals who were not bom in the village & $0.10^{* *}$ \\
& $(0.04)$ \\
Individuals who are not related to the chief & $0.07^{* *}$ \\
& $(0.03)$ \\
Individuals who identify as conflict victims & $0.06^{*}$ \\
& $(0.03)$ \\
Youth & $0.05^{*}$ \\
& $(0.03)$ \\
Individuals who are among the poorest in the village & $0.05^{*}$ \\
& $(0.03)$ \\
Women & 0.03 \\
& $(0.03)$ \\
\hline \multirow{2}{*}{ Overall } & $0.06^{* *}$ \\
\end{tabular}

N otes: *** Significant at $1 \%$; ** Significant at $5 \%$; Significant at $10 \%$. The table reports results from a least squares regression with matching on gender and gender treatment and with clustered standard errors. Marginal effects report differences in the share of endowment contributed to public good.

We look specifically at eight categories of people considered marginalized or disadvantaged in the Liberian context: people who are currently internally displaced in the country, ex-combatants, individuals not born in the village, individuals not personally related to the chief, youth, the poor, and women. $\mathrm{O}$ ur measures of membership in these categories are based generally on self-reported answers to our survey question; in addition, we categorize someone as a youth if he or she is 35 years old or younger. In general, these groups are evenly distributed across treatment and control communities with the exception of youth, who represent a larger share of the population in control communities.

Table 15 reports average contributions by members of each subset of marginalized groups (ordered by strength of the estimated treatment effect). In all cases, the average contribution of individuals from marginalized groups is higher in treatment communities than in control communities. These effects are large and statistically significant for people who continue to be internally displaced as a result of the war, for individuals born outside of the village, for those not personally related to the chief, for conflict victims, for youths, and for poorer respondents. The effect for internally displaced people is substantively very large and accounts for a very large share of the overall treatment effect: IRC program communities do better in large part because ID Ps living within them are more ready to contribute to projects that generate broad social benefits than are ID Ps elsewhere. It is also striking that while community members might be concerned in general that development projects are captured by the chief, the IRC CD R program changed people's 
expectations sufficiently to drive increased community contributions by those without ties to the preexisting leadership structure. ${ }^{13}$

\subsection{Social Inclusion}

We can also explore the impact of the CD R program - and specifically, the extent to which the program created more inclusive community processes - by examining survey data collected from the 24 randomly sampled respondents who made contributions decisions about how the community organized itself to select representatives, choose the project, and mobilize people to participate in the game. In our analysis, we focus on a variety of measures of inclusiveness, emphasizing knowledge/ awareness of the representatives and project, participation in the meetings, and attitudes about the quality of the representatives and projects selected.

Table 16 reports average community-level responses (i.e., the average share of community members giving a specific response across treatment or control communities) to a variety of survey questions. The final column reports average treatment effects estimated by taking a weighted average of the differences in outcomes between treated and untreated units in the women only and the mixed gender sites.

\section{Table 16: Measures of Inclusion and Democratic Governance}

\begin{tabular}{|c|c|c|c|}
\hline & $\begin{array}{l}\text { Control communities } \\
\text { (N) }\end{array}$ & $\begin{array}{l}\text { Treatment communities } \\
(\mathrm{N})\end{array}$ & $\begin{array}{l}\text { Difference } \\
\quad(\mathrm{se})\end{array}$ \\
\hline $\begin{array}{l}\text { Avg. share who attended the first } \\
\text { meeting }\end{array}$ & $\begin{array}{l}.50 \\
(41)\end{array}$ & $\begin{array}{l}.59 \\
(41)\end{array}$ & $\begin{array}{l}.09^{*} \\
(.05)\end{array}$ \\
\hline $\begin{array}{l}\text { Avg. share who reported other meetings } \\
\text { being held on the project }\end{array}$ & $\begin{array}{l}.44 \\
(41)\end{array}$ & $\begin{array}{l}.49 \\
(41)\end{array}$ & $\begin{array}{c}.05 \\
(.05)\end{array}$ \\
\hline $\begin{array}{l}\text { Avg. share who reported knowing } \\
\text { comm. Reps }\end{array}$ & $\begin{array}{l}.30 \\
(41)\end{array}$ & $\begin{array}{l}.37 \\
(41)\end{array}$ & $\begin{array}{l}.07 \\
(.05)\end{array}$ \\
\hline $\begin{array}{l}\text { Avg. share who reported funds would } \\
\text { "certainly" be put to good use }\end{array}$ & $\begin{array}{l}.80 \\
(41)\end{array}$ & $\begin{array}{l}.87 \\
(41)\end{array}$ & $\begin{array}{l}.07 * * \\
(.03)\end{array}$ \\
\hline $\begin{array}{l}\text { Avg. share who reported selected } \\
\text { projects were among "most important" } \\
\text { for village }\end{array}$ & $\begin{array}{l}.94 \\
(41)\end{array}$ & $\begin{array}{l}.95 \\
(41)\end{array}$ & $\begin{array}{l}.01 \\
(.02)\end{array}$ \\
\hline
\end{tabular}

Across measures, communities exposed to the CD R program appear to exhibit more inclusive processes. The strongest statistical results relate to the average share of respondents who attended the first meeting (which is nine percentage points higher in CDR communities) and the share who reported confidence in the community representatives (with CD R communities reporting that funds would "certainly" be put to good use at a rate seven percentage points higher). The other effects point in the direction of a positive impact of the CD R program, but are not statistically significant.

\footnotetext{
13 We emphasize that the results in Table 15 suggest that there were gains among marginalized groups, not that the gains were uniquely among more marginalized groups; indeed as can be seen from the table for some categories the gains, though positive, were less than average gains.
} 
These results are however generally weakened when we account for the differences in rurality across treatment and control sites.

\subsection{Democratic Practices}

The behavioral exercise also permits us to observe the extent to which the CD R program has altered how the community is governed. Recall that a key hypothesis implicit in the CD R model is that exposure to community-driven processes changes how people want to be governed, creating or strengthening a preference for democratic, transparent, and accountable governance. Moreover our main survey data suggested a greater willingness to engage in electoral processes.

In the context of the community-wide public goods game, we can ask whether CD R communities in fact employed more democratic practices in the selection of community representatives and projects.

Table 17: Behavioral Measures of Democratic Practices

\begin{tabular}{lccc}
\hline \hline & $\begin{array}{c}\text { Control communities } \\
(\mathrm{N})\end{array}$ & $\begin{array}{c}\text { Treatment } \\
\text { communities } \\
(\mathrm{N})\end{array}$ & $\begin{array}{c}\text { Difference } \\
(\mathrm{se})\end{array}$ \\
\hline Share of reps reporting that they were & .70 & .94 & $.24^{* * *}$ \\
selected in a community meeting & $(38)$ & $(34)$ & $(.08)$ \\
Share of reps reporting that projects were & .82 & .94 & $.12^{*}$ \\
selected at a community meeting & $(37)$ & $(36)$ & $(.07)$ \\
\hline
\end{tabular}

N otes: *** Significant at 1\%; ** Significant at 5\%; * Significant at 10\%. The table reports the average treatment effect on the treated, with matching according to assignment to the gender composition treatment; standard errors allow for heteroskedasticity across strata. Results are reported for village level outcomes.

Table 17 draws on survey evidence collected from the three community representatives who were presented to our teams as the people responsible for receiving the money and overseeing the implementation of the project. While we recognize that this measure potentially suffers from reporting bias, it has the advantage over more abstract survey questions in that it refers to specific and verifiable actions taken over the previous week. Moreover we note that our protocol provided no instructions about how these representatives or the community project were to be selected, and did not link selection to benefits.

The table reports the share of community representatives who reported to us that they were selected in a community meeting, as opposed to in private (i.e., by the chief or the elders). It also reports the share that said projects were selected in a public meeting.

Representatives in treatment communities report being selected in a community meeting at a rate 24 percentage points higher than in control communities. The CD R program also appears to have increased the likelihood that project selection is broadly participatory, although the effect is smaller in magnitude and the rate at which communities report undertaking participatory consultation begins from a high baseline. 


\section{Discussion}

\subsection{Confounding Factors?}

A common concern raised in any evaluation is how one knows with confidence that any differences between project (treatment) and comparison (control) communities are due to the program itself and not to other "confounding" factors. There are many factors that could in principle affect a program like this: the project areas could have different populations, geographies, conflict experiences, or other attributes when compared to the comparison communities. Perhaps they were selected because they were areas that were particularly receptive to outside intervention, or particularly willing to try out the project's participatory approach. Such considerations typically render program evaluation extremely difficult. In the presence of such concerns, readers often want to know if researchers have "controlled" for other factors. In the analysis provided here, however, we have typically not controlled for any other factors. The reason is that the approach used here, randomized intervention, provides exceptional confidence that such third factors are not in operation. We know with confidence that programs were not in operation in particular sites because of attributes of those sites; we know also that individuals were not exposed to the program because of any attributes of those individuals. While it is possible (and to some extent inevitable) that there are differences between program and control areas, there is, in this case, no reason to expect there to be any systematic biases one way or another.

For this reason, we can present the outcomes in their simplest form, as raw comparisons between treatment and control areas. Nevertheless, there could be two possible sources of confounding. O ne is that, by chance, program areas could happen to be different than control areas on some important criterion. In our analysis, we find evidence that this is true to some extentprograms were more likely to take place in rural areas. In response, we have undertaken robustness tests for the main results reported here and indicate the few cases in which this feature is of consequence.

The second type of concern is that selection into the program could induce other changes which affect outcomes but which are not directly attributable to the program (that is they are attributable to selection into the program but not to the program itself). Notably it is possible that once selected to a program a community becomes more likely to receive more (or less) aid from different sources. To examine this possibility, we collected data on other programs taking place in the area but find no evidence that selection into the CD R program resulted in differences in exposure to other development programs.

\subsection{Are Communities Just Telling Us What We Want to Hear?}

It is natural to ask whether the treatment effects we observe reflect real changes in attitudes and behavior, or rather the fact that CD R treatment communities learned what to say and how to act in order to please outsiders.

This concern is most relevant to the survey results. The surveys reveal extraordinarily high levels of support for democratic practices, very low levels of social tension, a rich associational life, 
and a strong willingness of individuals to be engaged in community problems. These levels - high across both treatment and control communities - may in part reflect the fact that our respondents are aware of the "right" answers to many of the survey questions. Liberians are bombarded with messages urging them to support democracy, to embrace women's rights, and not to treat people differently because of their tribe from donors and the national government. Indeed, this may be a part of the reason that the impact of the CD R program is harder to pick up in the survey results.

But for those treatment effects we do pick up in the survey - especially those that relate to levels of community tension and a willingness to embrace marginalized groups - it is a real possibility that CD R cued individuals to these issues without substantively changing their attitudes or behavior. The fact that the survey was carried out so soon after the program ended, and with the support of the IRC, reinforces this worry.

While this possibility cannot be completely ruled out, we think it is unlikely that this explanation accounts for the results in the behavioral games. First, it is highly unlikely that CD R communities contributed more because they thought this would help them get more funding from the IRC. The IRC was never mentioned in the behavioral games, and the games were implemented by an organization not linked to the IRC in any way, by teams that did not even know which communities had received the CDR treatment. Second, unlike with survey responses there is a real private cost in the games to taking an action motivated purely by a desire to please outsiders; moreover, the actions are taken in private and the benefits diffused over the community. Thus, the counterargument would have to be that exposure to the IRC CD R program greatly increased individuals' expectations that contributing would bring about more funding from NG O s. Given that many of the control communities have also received NGO projects, and that it could also be the case that communities underserved by NGO projects would have an even greater motivation to please outsiders, it seems unlikely that differential "desire to please" explains the strong differences in individual behavior across treatment and control communities. So, altogether we think the evidence is strong that the CDR program actually changed attitudes and patterns of behavior.

\subsection{External Validity: Is This a Typical IRC CDR Program?}

A final concern relates to the possibility that the results here are not general with respect to CD R programs elsewhere. For this reason, it is useful to assess whether this CD R program is typical of IRC efforts in other contexts. Are we observing these effects because the project was simply outstanding, with terrific on-the-ground leadership and a permissive context? Or are we finding these effects in spite of tremendous difficulties in program implementation?

Undoubtedly, this project - like most NGO initiatives in developing countries - was not without its staffing and implementation challenges. But to assess whether it was typical, we gathered some comparative data on CD R programs in other countries to try and put the Liberia project in context (see Table 18). 
Table 18: Comparative Data on CDR Programs

\begin{tabular}{lcccc} 
Categories & $\begin{array}{c}\text { Liberia } \\
\text { (IRC) }\end{array}$ & $\begin{array}{c}\text { Aceh } \\
\text { (BRA-KDP) }\end{array}$ & $\begin{array}{c}\text { Sudan } \\
\text { (IRC) }\end{array}$ & $\begin{array}{c}\text { Afghanistan } \\
\text { (NSP) }\end{array}$ \\
\hline Overall budget & $\$ 2,000,000$ & $\$ 2,668,840$ & $\$ 5,400,000$ & $\$ 14,135,514$ \\
\hline Number of beneficiaries & 54,000 & 29,461 & 57,319 & $1,822,907$ \\
\hline $\begin{array}{l}\text { Number of communities } \\
\text { with CDCs }\end{array}$ & 42 & 1,700 & 33 & 1500 \\
\hline $\begin{array}{l}\text { Average size of grant to } \\
\text { community }\end{array}$ & $\$ 17,346$ & $\begin{array}{c}\text { Ranged from } \$ 5,155 \\
\text { to } \$ 42,701 \\
\text { depending on phase }\end{array}$ & $\$ 35,000$ & $\$ 30,000$ \\
\hline $\begin{array}{l}\text { Number of staff working on } \\
\text { the CDR program }\end{array}$ & 18 & 74 & 60 & 615 \\
\hline $\begin{array}{l}\text { Rate of local staff tumover } \\
\text { Planned timeline for }\end{array}$ & No information & No information & $1-2$ per year & $1 / 3$ of staff per \\
year
\end{tabular}

If anything, the data suggest that the IRC program in Liberia was small-scale in funding, with a very short timeline, and a small staff relative to the number of communities served. While the Liberia project faced delays in starting up and project implementation, this seems to be a typical characteristic of CD R programs. Although we are not in position to speculate about how these program effects might be different in a larger, scaled-up CD R program, it is striking that we observe powerful evidence of behavioral and attitudinal change in what, for the IRC, is a short-term, smallscale effort. The implication is that it is not implausible that the effects of larger programs are stronger than those found here.

\subsection{Some Lessons Learned}

\subsubsection{Program Assumptions}

We have focused our discussion on differences between treatment and control communities and not on the levels of outcomes in each. In fact, however, it is clear that for many outcomes the levels of outcomes such as cohesion, democratic attitudes, or social acceptance, were very high both in treatment and control communities. These findings are inconsistent with some of the assumptions underscoring the CD R approach. Communities did not seem especially divided at the outset; there were few problems of acceptance; and there was little evidence of a crisis in leadership or a sense of political exclusion. Having such information before the evaluation started could have led to the collection of a more appropriate set of measures, but also could have helped to shape the design of the program. In standard practice, baseline measures are often taken only after a program design has been completed; our results suggest, however, that this may be too late. 


\subsubsection{Ethics of Randomization}

An obvious concern with the use of randomization for the delivery of aid in a post-conflict setting is that it could give rise to jealousies between communities that do and do not receive benefits and could conceivably lead to conflict. On the other hand, there are clear benefits; not only is the procedure equitable in the sense of giving all equally needy communities an equal opportunity to benefit, it is also transparent. Communities can see how they were or were not selected and do not have to resort to theories of systematic exclusion or favoritism. Because of these concerns, we monitored the lottery process for early indications of conflict risks. Reports from the field strongly indicated that not only were there no conflicts resulting from the randomization, but that communities did indeed view the process favorably and appreciated the equity of the procedure. From our own fieldwork on this project, it seems clear that the views of Liberians resonate with the government's and NG O's emphasis on the importance of "transparency," and that they saw the public lottery to decide project allocation as a transparent and fair procedure. While randomization should continue to be monitored closely, this experience suggests that the potential for a randomized approach is greater than many have suggested.

\subsubsection{Measures}

Many of the outcomes of interest for this study - attitudes, cohesion, and acceptance- are intangible. A standard approach to measuring such outcomes is to use surveys of random samples of respondents. While there are great benefits to this approach, as described in Section 6.2 above, there are also real concerns of reporting bias. In response, we turned to the use of behavioral games. We did so with some apprehension, however, viewing the behavioral tests as exceptionally difficult tests of program impact. In fact, this approach yielded some of our strongest results. We believe this experience can serve as an encouragement for others hoping to move beyond surveys to gather compelling measures of abstract outcomes.

\section{Conclusions and Implications}

This paper covers a great deal of ground, with measures drawn from the panel survey as well as behavioral games to test hypotheses linking CD R to a wide variety of outcomes. How do we make an overall assessment of program impact based on all of these different measures? $\mathrm{On}$ some measures these effects are significant; on many, they are not. Moreover, ideally for each measure we would have a quantitative target (other than zero) against which we could examine our estimated effect sizes. In the absence of good information about the potential effects of programs of this form, however, identifying such targets is very difficult; it is simply not known for example how "large" an effect a CDR program can have on community cohesion. Moreover, for many of the outcomes considered here, there is no widely recognized metric on which such goals could be based. As the number of studies of this form increase, goal-setting of this form may become easier.

In the meantime, the approach we have used is to examine outcomes against a "null hypothesis" of no effect. We ask for each separate outcome what we would expect to see if the IRC CD R program in fact had no effect on people's material circumstances, attitudes, or behaviors as reported in the survey and examine how different what we observe is from this null outcome. This is a standard statistical approach. However, in this case (and often in others), looking for "statistically significant" differences between treatment and control groups outcome by outcome may not be the best way to provide an overall assessment of the results. For an overall assessment, we should ask 
not just about outcome-by-outcome results, but whether there are larger patterns across outcomes and how likely they would be to appear by chance if the CD R program in fact had no impact.

Call an effect estimate "supportive" if it is consistent with the hypothesized effect of the CD R program. If the program had no impact or no consistent impact, then we would expect to find a roughly equal number of supportive and unsupportive effect estimates, and about $5 \%$ would appear to be supportive and "statistically significant." What we actually find is quite different. The direction of the effect estimates is far more often supportive than unsupportive. And when the estimated treatment effects are statistically significant, they are almost always in the supportive direction. For over $20 \%$ of our 90 outcome measures reported here, we find statistically significant effects in a direction supportive of a positive CD R program effect. Moreover, for $73 \%$ of the outcome measures in the survey data, we estimate a positive effect of the CD R program. For only $2 \%$ of cases is there a priori evidence of a significant adverse effect and in these cases the adverse effects can be accounted for by initial variation in the baseline. These patterns are summarized in Figure 1 below. They are consistent with, and strongly reinforced by, the positive assessment of program impact emerging from our behavioral measures.

Figure 1: Summary of statistical results

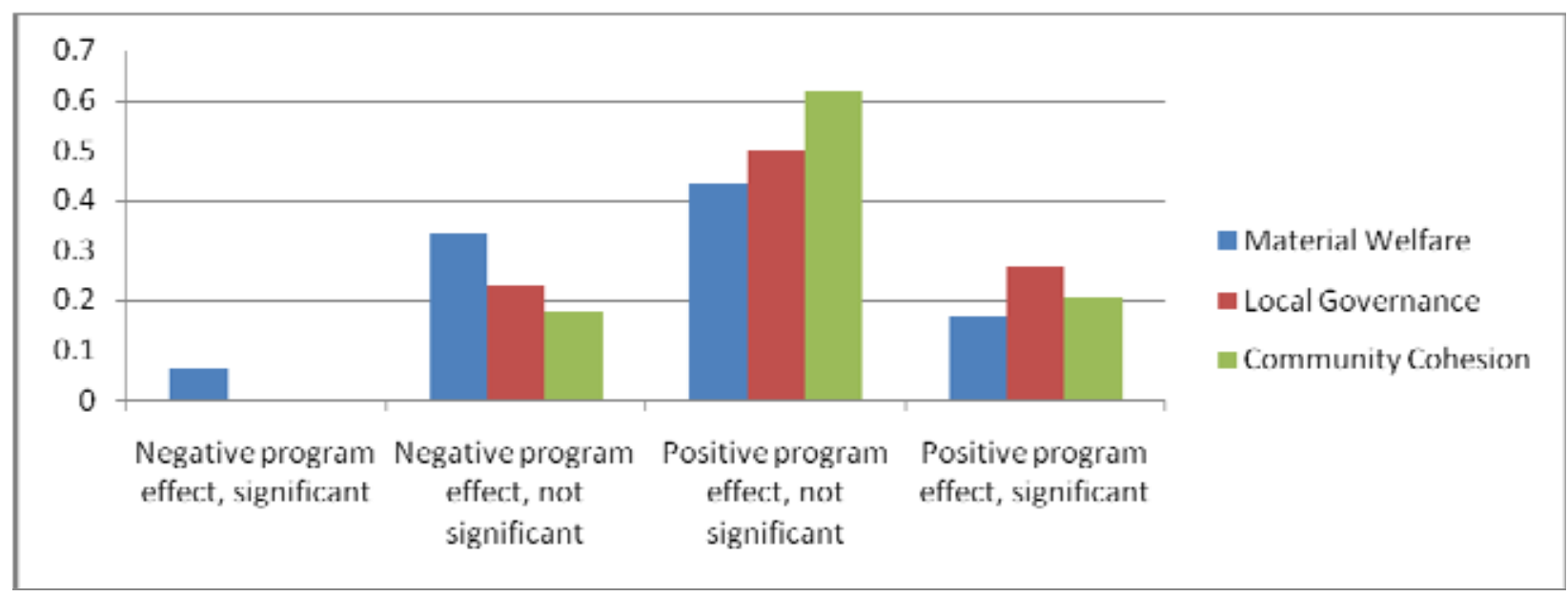

The overall assessment then is positive. However, there is much variation across objectives. Table 19 provides a summary of which hypotheses found strong or weak support in this evaluation. Some hypotheses receive strong support and some receive no support at all. Taken together, the data are generally supportive of the following conclusions:

- The CD R program had a measurable, positive impact on the level of community cohesion. Communities exposed to the CD R program appear better able to act collectively after the program's completion to improve their own welfare. The evidence for this in the surveys is relatively weak, but our behavioral measures provide strong evidence that CD R communities can significantly outperform control communities in raising funds to implement a community project.

- E x posure to CD R also appears to have increased social inclusion in beneficiary communities, especially for marginalized groups. The behavioral evidence on this is powerful, with greater knowledge and awareness of the community project and faith in the representatives and projects chosen. 
Moreover, traditionally marginalized groups made significantly higher contributions to the community project in CD R communities. Survey evidence is also supportive of this conclusion, with individuals in CD R communities reporting less social tension and exhibiting greater acceptance of traditionally marginalized groups.

- The CD R program also reinforced democratic values and practios. The evidence in the surveys provides some evidence for greater support for elections and participatory processes in treatment communities. The behavioral games demonstrate these values in practice, with a higher likelihood of democratic selection processes for community representatives and projects in communities that experienced CD R. Baseline support for these values and practices were however high and there is no evidence that the program altered these values among our sample of town chiefs.

\section{Table 19: Summary of Substantive Results}

\section{\# HYPOTHESIS \\ OUTCOME}

1Welfare

1.1

The program will result in improved access to health,

education, water sources and other basic amenities

Improved access to

education

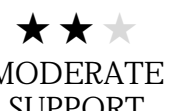

SUPPORT

1.2

The program will result in greater opportunities for income generation and wealth creation

Weak evidence for gains in small asset holdings and employment

\section{Local Govemance}

The program will change how individuals think about

2.1 decision making at local levels, in favor of transparency, accountability, and inclusiveness.

Most respondents already hold these attitudes. More transparent approaches used in behavioral games.

Most chiefs already hold these attitudes. No gains in treatment areas.

Weak gains on multiple measures and significant rise in interest in elections.

Increased trust in community leaders on multiple measures.

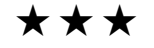

HYPOTHESIS SUPPORTED 


\section{Community Cohesion}

The program will result in greater acceptance of

3.1 individuals, specifically conflict victims, displaced persons and ex-combatants

High baseline levels of

acceptance. Some evidence

of greater inclusion of poor

and ex-combatants.

Weak effect on existence of

tensions but evidence that

tensions less likely to

become violent

Strong evidence from

behavioral measures that

communities can work

together more effectively.
WEAK

SUPPORT

3.3

The program will enhance the community's ability to act collectively

groups and a greater ability to resolve tensions non-

violently

- There is little evidence of positive improvements in material well-being related to the CD R program. While the data do suggest an improvement in local public goods - consistent with the focus of communities on the construction of community facilities - this does not appear to have translated into household-level welfare improvement. The main finding on welfare is that access to education improves significantly. Evidence for gains in livelihoods and asset holdings are however weak.

As studies of this form accumulate, it will be useful to put them in the context of evaluations of CD R projects by IRC and other implementing agencies. In anticipation of such a comparison, we contrast the findings with our initial expectations going into the project. In fact, we did not expect to find nearly as strong and positive results as those reported above. We expected that we might find some evidence of attitudinal change in the survey data, which we thought would most likely reflect an "indoctrination effect" more than any deep change in beliefs and practice. Thus, we expected that we would probably not find evidence of improved ability to cooperate to provide public goods in the behavioral games. We thought it possible that we might find some evidence of behavioral effects in how CD R-treated communities organized to choose community representatives and projects in the behavioral games. But we were doubtful that actual contributions would differ systematically across treatment and control groups.

These pessimistic expectations were based on our own experiences with aid projects in developing countries, and on a large academic literature that casts doubt on the ability of foreign aid to have much real impact on deeply rooted patterns of social cooperation, conflict, and local governance structures. Such studies point to the scope for adverse effects on political dynamics (Gugerty and Kremer 2008) and to the risks of misuse of project assets (Ensminger, 2007). Even if we ignore concerns about the possible capture of projects by local elites or about the robustness of local political cultures, another reason to expect to find little apparent impact is that the outcomes in question - attitudes and practices concerning governance and social cohesion - are so hard to measure (Murphy 1990). D evelopment practitioners are at the beginning of the road in terms of understanding how to conceptualize and operationalize these project aims. Finally, an 18-month project of this sort would seem inherently limited in how much it can achieve, given the scale of the problems compared to the time, staff, and other resources available.

Under such circumstances we find the evidence of positive program impact - which for a number of the hypothesized outcomes is clear and fairly unambiguous because this was a randomized controlled study - to be remarkable. O ur results suggest that patterns of social 
cooperation and political practices are in fact malleable. Moreover, community-driven projects have the potential to increase faith and trust in village institutions perhaps by giving community leaders an opportunity execute projects for the benefit of villagers. While we are not in a position to say anything about the long-term sustainability of these impacts, the fact that positive effects are observed nearly six months after the program's conclusion is reassuring. Further research is needed to establish whether the beneficial impacts of CD R programs persist long after the program's conclusion.

We find it particularly interesting that the evidence for a causal impact of the CD R program seems if anything stronger in the behavioral measures than in the attitudinal survey data. Attitudinal surveys are the standard tool for relatively rigorous evaluations of post-conflict governance aid programming. The results presented above may suggest that even so they are very noisy measures that may fail to pick up behavioral change (that one might have thought would be hard to accomplish). Future work on evaluation might try to develop an array of behavioral measures ranging from a community-wide public goods game like that used here, to simpler and more targeted behavioral measures that could be more easily implemented. 


\section{References}

Alesina, Alberto and Eliana La Ferrara. 2005. "Ethnic D iversity and Economic Performance," Journal of E conomic L iterature 43 (3): 721-761.

Arcand, J. and Bassole, L. 2007. "D oes Community D riven D evelopment Work? Evidence from Senegal" Working Paper CERDI .

Barron, Patrick, Macartan Humphreys, Laura Paler, and Jeremy Weinstein. 2009. "Community Based Reintegration in Aceh: Assessing the Impacts of BRA-KD P." World Bank: Indonesian Social D evelopment Paper 12, A ugust.

Bowles, Samuel and Herbert Gintis. 2004. "Persistent Parochialism: Trust and Exclusion in Ethnic Networks," Journal of $\mathrm{E}$ conomic Behavior and O rganization 55(1): 1-23.

Cliffe, Sarah, Scott G uggenheim and Markus Kostner. 2003. "Community-D riven Reconstruction as an Instrument in War-to-Peace Transitions "CPR Working Papers, No. 7

Ensminger, Jean. 2007. "G etting to the Bottom of Corruption: A Case Study in Community D riven D evelopment," Unpublished manuscript, Caltech.

G ugerty, Mary Kay and Michael Kremer, "O utside Funding and the Dynamics of Participation in Community Associations", A merican Journal of Political Science, 52 (3), 585-602

Labonne, Julien and Robert S. Chase. 2008. D o Community-D riven D evelopment Projects Enhance Social Capital? Evidence from the Philippines, World Bank Policy Research Working Paper No. 4678

Mansuri, G hazala and Vijayendra Rao. 2004. "Community-Based and -D riven D evelopment: A Critical Review," W orld Bank Research 0 bserver, 19(1): 1-39.

Moyo, D ambisa. 2009. D ead A id. New York: Farrar, Straus and Giroux.

Murphy, William P. 1990. "Creating the Appearance of Consensus in Mende Political Discourse," A merican A nthropologist 92 (1): 24-41.

Nunn, Nathan. 2008. “The Long Term Effects of Africa's Slave Trades," Q uarterly Journal of E conomics 123(1): 139-176.

Richards, Paul et al. 2005. "Community Cohesion in Liberia," Social D evelopment Paper 21, The World Bank.

The World Bank. 2003. Break ing the C onflict Trap: Civil W ar and D evelopment Policy. Washington, D C: The World Bank. 


\section{Appendix A}

Table 19: Comparison of Treatment and Control

\begin{tabular}{|c|c|c|c|c|c|}
\hline Demographic variables & Control & Treatment & Difference & RCSE & p-value \\
\hline Sex & 0.49 & 0.49 & 0.00 & 0.01 & 0.84 \\
\hline Age & 26.95 & 26.78 & -0.17 & 0.58 & 0.77 \\
\hline Married now & 0.34 & 0.35 & 0.00 & 0.02 & 0.78 \\
\hline Some secondary schooling & 0.05 & 0.04 & -0.01 & 0.01 & 0.15 \\
\hline Mandingo & 0.15 & 0.20 & 0.05 & 0.09 & 0.59 \\
\hline Muslim & 0.17 & 0.22 & 0.05 & 0.09 & 0.63 \\
\hline Conflict Injury & 0.05 & 0.05 & 0.00 & 0.01 & 0.64 \\
\hline D isplaced & 0.78 & 0.75 & -0.03 & 0.02 & 0.22 \\
\hline Fighter & 0.04 & 0.04 & 0.00 & 0.01 & 0.71 \\
\hline Distance to services & Control & Treatment & Difference & RCSE & p-value \\
\hline Water & 9.96 & 9.99 & 0.03 & 0.99 & 0.97 \\
\hline Market & 84.44 & 121.44 & 37.00 & 18.08 & 0.04 \\
\hline Transport & 66.52 & 98.83 & 32.30 & 20.44 & 0.11 \\
\hline Primary & 27.35 & 27.36 & 0.01 & 4.46 & 1.00 \\
\hline Secondary school & 74.51 & 101.40 & 26.89 & 12.57 & 0.03 \\
\hline Clinic & 63.73 & 109.94 & 46.21 & 19.91 & 0.02 \\
\hline Latrine & 7.70 & 4.72 & -2.98 & 1.71 & 0.08 \\
\hline Household assets & Control & Treatment & Difference & RCSE & p-value \\
\hline Rooms & 2.98 & 3.17 & 0.19 & 0.11 & 0.07 \\
\hline Sheep G oat & 0.17 & 0.19 & 0.02 & 0.09 & 0.80 \\
\hline Chicken & 6.93 & 8.46 & 1.53 & 0.92 & 0.10 \\
\hline Fowl & 0.29 & 0.15 & -0.13 & 0.07 & 0.07 \\
\hline Bamboo & 2.09 & 2.38 & 0.29 & 0.17 & 0.08 \\
\hline Wooden & 0.36 & 0.38 & 0.02 & 0.07 & 0.83 \\
\hline Foam & 0.64 & 0.52 & -0.13 & 0.08 & 0.10 \\
\hline Straw & 1.17 & 1.38 & 0.21 & 0.11 & 0.06 \\
\hline Buckets & 2.13 & 2.08 & -0.04 & 0.08 & 0.62 \\
\hline Doors & 2.13 & 2.35 & 0.22 & 0.18 & 0.21 \\
\hline Radio & 0.60 & 0.57 & -0.04 & 0.04 & 0.42 \\
\hline Rice & 5.15 & 5.40 & 0.25 & 0.31 & 0.43 \\
\hline Characteristics of houses & Control & Treatment & Difference & RCSE & p-value \\
\hline Thatch & 0.48 & 0.37 & -0.11 & 0.06 & 0.08 \\
\hline Zinc & 0.37 & 0.45 & 0.08 & 0.06 & 0.15 \\
\hline Mud bricks or better & 0.16 & 0.13 & -0.02 & 0.05 & 0.64 \\
\hline Piped water & 0.20 & 0.11 & -0.10 & 0.03 & 0.01 \\
\hline Do you agree ... & Control & Treatment & Difference & RCSE & p-value \\
\hline Should Question Leaders More & 0.60 & 0.56 & -0.05 & 0.05 & 0.35 \\
\hline Leaders Should Not Favor Family & 0.96 & 0.96 & 0.01 & 0.01 & 0.59 \\
\hline All Should Participate & 0.55 & 0.61 & 0.06 & 0.04 & 0.19 \\
\hline Equal Rights For Women & 0.66 & 0.67 & 0.02 & 0.04 & 0.63 \\
\hline Prefer Elections For Chief & 0.89 & 0.91 & 0.02 & 0.03 & 0.45 \\
\hline $\begin{array}{l}\text { Q 80, In the past } 6 \text { months, have you done any of the } \\
\text { following (participated in, contacted, notified about a } \\
\text { problem ...) }\end{array}$ & Control & Treatment & Difference & RCSE & p-value \\
\hline Town Meeting & 0.86 & 0.92 & 0.06 & 0.03 & 0.02 \\
\hline Speech & 0.75 & 0.82 & 0.07 & 0.03 & 0.01 \\
\hline Met a Chief & 0.55 & 0.65 & 0.10 & 0.04 & 0.02 \\
\hline Election Campaign & 0.62 & 0.65 & 0.04 & 0.03 & 0.22 \\
\hline Voted & 0.85 & 0.91 & 0.05 & 0.02 & 0.01 \\
\hline Contacted Police & 0.08 & 0.11 & 0.03 & 0.02 & 0.17 \\
\hline Contacted G overnment Official & 0.09 & 0.10 & 0.01 & 0.02 & 0.49 \\
\hline
\end{tabular}




\begin{tabular}{lccccc}
$\begin{array}{l}\text { Q83, In the past 6 months has there been a community } \\
\text { initiative to (rebuild, repair, do ..) }\end{array}$ & Control & Treatment & Difference & RCSE & p-value \\
\hline School Or Clinic & 0.38 & 0.41 & 0.03 & 0.04 & 0.43 \\
Roadbrushing & 0.79 & 0.85 & 0.06 & 0.04 & 0.17 \\
Regrade Road & 0.20 & 0.25 & 0.05 & 0.03 & 0.09 \\
Hand Pipe & 0.38 & 0.34 & -0.04 & 0.04 & 0.27 \\
Security & 0.22 & 0.16 & -0.06 & 0.03 & 0.05 \\
Agriculture & 0.49 & 0.54 & 0.05 & 0.04 & 0.19 \\
Church Or Mosque & 0.36 & 0.32 & -0.04 & 0.04 & 0.36 \\
& & & & & \\
Q86, Are any of the following types of association & Control & Treatment & Difference & RCSE & p-value \\
active in your town? & 0.50 & 0.49 & -0.01 & 0.04 & 0.80 \\
Susu & 0.81 & 0.86 & 0.05 & 0.04 & 0.15 \\
Koo & 0.75 & 0.78 & 0.03 & 0.04 & 0.46 \\
Women's Action & 0.53 & 0.53 & 0.00 & 0.04 & 0.99 \\
Farm G roup & 0.36 & 0.39 & 0.03 & 0.05 & 0.60 \\
Water Committee & 0.48 & 0.52 & 0.04 & 0.04 & 0.32 \\
Religious Association & 0.59 & 0.63 & 0.03 & 0.05 & 0.50 \\
PTA School & 0.58 & 0.59 & 0.01 & 0.04 & 0.86 \\
Sports Music D rama & 0.10 & 0.06 & -0.04 & 0.03 & 0.15 \\
Other & & & & &
\end{tabular}

To what extent do differences such as the following tend to divide people in your town? ( 0 = " not at all," 1 = " somewhat or very much." )

$\begin{array}{lccccc}\text { Differences on Wealth } & & & & \\ \text { Differences on G ender } & 0.28 & 0.27 & -0.02 & 0.04 & 0.66 \\ \text { Differences on Age } & 0.31 & 0.32 & 0.01 & 0.04 & 0.83 \\ \text { Differences on Returnees } & 0.32 & 0.30 & -0.02 & 0.04 & 0.58 \\ \text { Differences on Religion } & 0.27 & 0.24 & -0.03 & 0.04 & 0.42 \\ \text { Differences on Ethnic } & 0.29 & 0.24 & -0.05 & 0.04 & 0.21 \\ \text { Differences on Education } & 0.30 & 0.25 & -0.06 & 0.04 & 0.20 \\ \text { Differences on Other } & 0.25 & 0.22 & -0.03 & 0.04 & 0.40 \\ \text { onflict Incidents } & 0.09 & 0.05 & -0.04 & 0.02 & 0.05 \\ \text { Theft Chickens } & \text { Control } & \text { Treatment } & \text { Difference } & \text { RCSE } & \text { p-value } \\ \text { Theft Items } & 0.25 & 0.23 & -0.02 & 0.03 & 0.54 \\ \text { Fighting } & 0.21 & 0.16 & -0.05 & 0.03 & 0.03 \\ \text { Weapons } & 0.02 & 0.03 & 0.01 & 0.01 & 0.40 \\ \text { Violence } & 0.08 & 0.06 & -0.02 & 0.02 & 0.23 \\ \text { Know name of... } & 0.04 & 0.05 & 0.00 & 0.01 & 0.83 \\ \text { President } & \text { Control } & \text { Treatment } & \text { Difference } & \text { RCSE } & \text { p-value } \\ \text { Speaker } & 0.98 & 0.97 & -0.01 & 0.01 & 0.52 \\ \text { Representative } & 0.14 & 0.12 & -0.02 & 0.02 & 0.25 \\ \text { Superintendent } & 0.39 & 0.41 & 0.01 & 0.05 & 0.79 \\ \text { District Commissioner } & 0.22 & 0.19 & -0.03 & 0.04 & 0.42 \\ \text { District Development Committee Chair } & 0.20 & 0.22 & 0.02 & 0.04 & 0.71 \\ \text { last month... } & 0.08 & 0.10 & 0.02 & 0.02 & 0.46 \\ \text { Visit Town } & \text { Control } & \text { Treatment } & \text { Difference } & \text { RCSE } & \text { p-value } \\ \text { Visit Capital } & 0.86 & 0.85 & -0.01 & 0.03 & 0.79 \\ \text { Visit Monrovia } & 0.77 & 0.79 & 0.02 & 0.04 & 0.58 \\ \text { UNMIL Radio } & 0.67 & 0.69 & 0.02 & 0.04 & 0.56 \\ & 0.60 & 0.62 & 0.02 & 0.04 & 0.70\end{array}$

